\title{
Benthic foraminiferal assemblages and test accumulation in coastal microhabitats on San Salvador, Bahamas
}

\author{
Andrea Fischel $^{1}$, Marit-Solveig Seidenkrantz ${ }^{1}$, and Bent Vad Odgaard ${ }^{2}$ \\ ${ }^{1}$ Centre for Past Climate Studies, and iClimate, Department of Geoscience, \\ Aarhus University, Hoegh-Guldbergs Gade 2, 8000 Aarhus, C, Denmark \\ ${ }^{2}$ Department of Geoscience, Aarhus University, Høegh-Guldbergs Gade 2, 8000 Aarhus C, Denmark
}

Correspondence: Marit-Solveig Seidenkrantz (mss@geo.au.dk)

Received: 24 November 2017 - Revised: 22 September 2018 - Accepted: 3 October 2018 - Published: 14 November 2018

\begin{abstract}
Benthic foraminiferal populations were studied in a shallow bay of San Salvador Island, the Bahamas. Surface sediments and marine macrophytes were collected from 14 sample sites along a $500 \mathrm{~m}$ transect at Grahams Harbour to investigate the foraminiferal assemblage in each microhabitat and to test the link between dead foraminiferal test accumulation patterns and living epiphytic and sedimentary foraminiferal assemblages, macrophyte distribution, and environmental gradients. The analyses include grain size measurements, macrophyte biomass quantification, and qualitative and quantitative studies of benthic foraminifera. The foraminifera found attached to macrophytes differed between macrophyte habitats. However, a correlation between these living communities and the dead assemblages in the sediments at the same sites could not be observed. Principal component analysis (PCA) and redundancy analysis (RDA) suggest that the presence of the macroalgae Halimeda explains $16 \%$ of the residual faunal variation in the dead foraminiferal assemblage after the effects of sorting according to fall speed are partialled out. The RDA also reflects a positive correlation between foraminifera larger than $1.0 \mathrm{~mm}$ in diameter and the $0.25-0.5 \mathrm{~mm}$ sediment grain size, indicating sedimentological processes as the main factor controlling the sedimentary epiphytic foraminiferal assemblages. These sedimentary processes overprint most effects of ecological features or macrophyte-specific association.
\end{abstract}

\section{Introduction}

Benthic foraminifera generally show high abundances and diversity in tropical shallow marine realms (e.g. Brasier, 1975; Boltovskoy and Wright, 1976) where they inhabit surface sediments and submerged macrophyte communities (Bock et al., 1971; Brasier, 1975; Culver and Buzas, 1982; Buchan and Lewis, 2009). Their tests are among the most important contributors to the sediment matrix in nearshore environments in tropical regions (Berkeley et al., 2008; Darroch, 2012). However, the typically oligotrophic waters with low organic carbon and nutrient content as well as the often coarse-grained sediments and strong currents in nearshore sediments in the Caribbean region result in severe food limitation for local microorganisms, including benthic foraminifera (Lipschultz et al., 2002; Buchan and Lewis, 2009). Consequently, the number of benthic foraminiferal taxa living in surface sediments is generally low (Wright, 1964; Murray, 1991; Morgan and Lewis, 2010). Instead, as more nutrients are available in the proximity of marine macrophytes (Murray, 1970), the majority of nearshore foraminifera in these environments have adopted an epiphytic life modus, living motile or permanently to temporarily attached to macrophyte substrates, i.e. leaves, exposed rhizomes, algae thalli and seagrasses (Cushman, 1922; Wright and Hay, 1971; Waszczak and Steinker, 1978; Langer, 1993; Alve, 1999; Wilson, 1998, 2007, 2008; Wilson and Ramsock, 2007). Distinctive epiphytic foraminiferal communities develop on different macrophyte taxa (Langer, 1993; Fujita and Hallock, 1999; Ribes et al., 2000; Wilson, 2000, 2008; Fujita, 2004; Debenay and Payri, 2010), leav- 
ing tests of dead foraminifera to accumulate in the sediment (Steinker and Clem, 1984; Darroch, 2012).

As epiphytic foraminifera are very abundant in nearshore environments, especially in tropical and subtropical regions (Renema and Troelstra, 2001; Renema, 2006), they are often used in palaeoecological studies as indicators of the presence of macroalgae or seagrasses or for determining the degree of allochthonous influence in assemblages of deeper-water sites (Thomas and Schafer, 1982; Davaud and Septfontaine, 1995; see also review of Reich et al., 2015). However, several studies have indicated a disparity between the living foraminiferal populations (biocoenoses) found in macroalgae and standing seagrass and macroalgae and the dead assemblages (thanatocoenoses) found in the sea-floor sediment below (e.g. Martin, 1986; Martin and Wright, 1988; Buchan and Lewis, 2009), a finding which questions sedimentary assemblages of epiphytic species as a reliable proxy for past macroalgal and seagrass cover. Nevertheless, relatively few studies exist of modern benthic foraminifera in environments potentially dominated by epiphytes (Langer, 1993; Hickmann, 2005; Buchan and Lewis, 2009; Darroch et al., 2016), with some of these studies concentrating on specific species and/or preservation rather than assemblage composition (Martin, 1986; Darroch et al., 2016). Other studies suggest that a potential mismatch between biocoenosis and thanatocoenosis is mainly relevant at deeper-water sites (e.g. Martin and Wright, 1988). The cause of potential discrepancy has also been discussed (e.g. Martin and Wright, 1988; Darroch et al., 2016). As a result, the assumption of a direct relation between living epiphytic communities and dead assemblages needs further testing. In this context, the distribution of living and fossil foraminiferal assemblages in the sediment and epiphytic habitats helps assess the significance of post-mortem transport and accumulation from currents and wave actions (Kotler et al., 1992; Berkeley et al., 2008). Comparison of living populations and dead assemblages also provides a means to evaluate the impact of abrasion and dissolution of foraminiferal tests, which may cause important faunal and abundance differences between the biocoenosis and the thanatocoenosis (Wilson, 2006, 2010).

A multiplicity of shallow marine habitats is found in the oligotrophic water environments of the Bahamas archipelago (e.g. Cushman, 1931; Hofker, 1956; Bock et al., 1971; Culver and Buzas, 1982; Wilson, 1998, 2000). On San Salvador Island, one of the outermost islands of the Bahamas, epiphytic habitats like seagrass meadows are well established and widely distributed, especially along the northern shore of the island. The area is directly connected to the Atlantic Ocean and is influenced by the Antilles Current (Gerace et al., 1998), providing stable water temperatures throughout the annual cycle. Finally, a low human population density and little touristic infrastructure on the island result in limited effects from pollution, eutrophication, anthropogenic disturbance and other human impacts on the shallow marine lagoons (Buchan and Lewis, 2009). The island is thus an ex- cellent site for shallow benthic foraminiferal habitat research, not the least for the study of epiphytic species.

The purpose of the present study is to test the distributional pattern of benthic foraminifera in living populations and dead assemblages associated with sediment as well as macrophytes. The main focus is a comparison between the epiphytic foraminiferal community and various types of macrophyte habitats as well as a comparison between the epiphytic and surface sediment communities to test for similarities and differences between biocoenosis and thanatocoenosis, i.e. whether the thanatocoenosis in the regions of macrophytes is in fact more enriched in epiphytic foraminiferal tests than areas without vegetation. We will also test for possible links between sediment grain size and dead foraminiferal test distributions to evaluate the possible role of sediment transport in the distribution of epiphytes in the thanatocoenosis. These tests will provide important information on the reliability of sedimentary assemblages of epiphytic foraminifera as indicators of macrophytes.

\section{Study area}

San Salvador is one of the outermost islands of the eastern part of the Bahamas archipelago and is located approximately $600 \mathrm{~km}$ off the Florida coast. With a size of $11 \times$ $19 \mathrm{~km}$, it is one of the smaller islands in the Bahamas (Gerace et al., 1998; Gould and Vermette, 2005) (Fig. 1a). Topographically isolated from the main Bahama Banks (Great and Little Bahamas Bank) as a submarine carbonate platform including the majority of the Bahamas islands, it is surrounded by marine water basins reaching up to $4000 \mathrm{~m}$ of water depth (Gerace et al., 1998). Due to its open, unprotected connection to the Atlantic Ocean, San Salvador is year-round exposed to relatively strong trade winds, primarily from the NE to SE, and associated high-energy waves (Thomas A. McGrath, unpublished data, 1993). The island is furthermore commonly subject to hurricanes primarily reaching San Salvador from the SE and $\mathrm{E}$ with the main path along the archipelago (Caribbean Hurricane Network, 2011). Such hurricanes can result in significant beach erosion (Curran et al., 2001).

The hydrographic conditions of offshore regions of the island are characterized by the Antilles Current, part of the North Atlantic Subtropical Gyre (Gerace et al., 1998), which transports equatorial waters to San Salvador, causing relatively cool sea-surface temperatures (SSTs) in the summer (range $22-32^{\circ} \mathrm{C}$ ) and a relatively warm SST during winter $\left(17-27^{\circ} \mathrm{C}\right)$ (Shaklee, 1994). However, nearshore waters are primarily affected by the longshore current, which is induced by north-easterly trade winds and is strongest during winter. During summer months, the wind direction shifts to predominantly south-eastern, resulting in a weakening of the coastal current (Thomas A. McGrath, unpublished data, 1993; Gerace et al., 1998). Despite a strong current and often heavy winds, shallow carbonate banks and reef formations around 

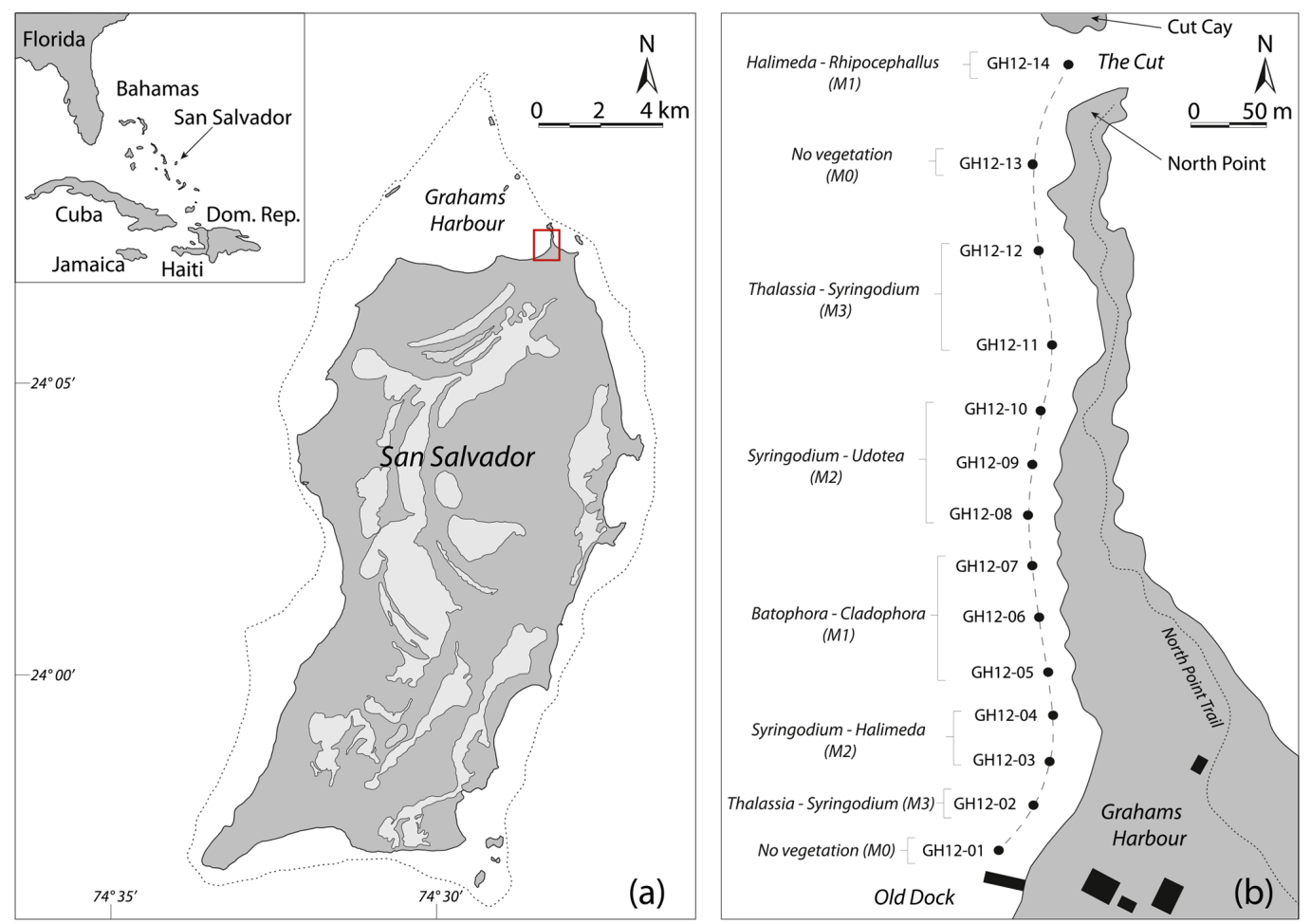

Figure 1. (a) Map of the Bahamas in the western North Atlantic Ocean and location map of San Salvador; modified after Robinson and Davis (1999). Light grey areas: distribution of fresh and saltwater lakes on San Salvador. The dotted line indicates water depths less than $10 \mathrm{~m}$. Red square: study area at Grahams Harbour. (b) Schematic map of the studied transect (dashed line) with 14 sample sites from the Old Dock (site GH12-01) to the Cut (site GH12-14), with a water depth of approx. $1 \mathrm{~m}$. The sample sites are categorized into microhabitats M0 (vegetation absent), M1 (sparse vegetation), M2 (moderate vegetation) and M3 (dense vegetation) in accordance with the dominant macrophyte species in the respective habitats. Black rectangles indicate the location of building structures.

the island create protected habitats for marine endemic flora and fauna (Fig. 1a).

One such protected basin is the $3 \mathrm{~km}$ long embayment Grahams Harbour. It is located at the northern tip of San Salvador Island at $24^{\circ} 07^{\prime} 24^{\prime \prime} \mathrm{N}, 74^{\circ} 27^{\prime} 30^{\prime \prime} \mathrm{W}$, and bounded by San Salvador to the south, the coastline of North Point to the east, and a series of reefs and small islands to the north (Fig. 1) (Adams, 1980; Gerace et al., 1998). The basin reaches a maximum water depth of ca. $6 \mathrm{~m}$ (average depth ca. $1.5 \mathrm{~m}$ ) and in its deepest part sediments consist of up to $4 \mathrm{~m}$ thick calcareous ooze and bioclastic sand resting on top of hard bedrock sediments. The ooze is mainly composed of poorly sorted fragments of calcifying green algae of the genus Halimeda, corals and sponges, as well as benthic foraminifera and microgastropods (Colby and Boardman, 1989; Darroch, 2012; Darroch et al., 2016). In the shallow margins of the basin, the unconsolidated ooze can be as shallow as $5-10 \mathrm{~cm}$. The subsurface geology consists of Holocene sand and limestone stratigraphically belonging to the North Point Member of the Rice Bay Formation (Colby and Boardman, 1989; Hearty and Kindler, 1993; Mylroie and Carew, 2010).
Surrounded by reefs and barrier islands to the north and east, Grahams Harbour remains open to deeper waters in the west (Armstrong and Miller, 1988). This results in a windward high-energy lagoon that is highly affected by the longshore currents entering through a narrow opening, the Cut, between North Point and Cut Cay, and moving southwards along the shore (Gerace et al., 1998) (Fig. 1b). No detailed long- or short-term hydrographic monitoring of this current exists, but during sampling we clearly observed the highest current velocities closest to the Cut and lower energy levels further into the bay, a phenomenon that has previously been described by Buchan and Lewis (2009). The current is strongly affected by tidal action with a general tidal range of $50-90 \mathrm{~cm}$ at near-coastal sites (source: NOAA/NOS/COOPS, referenced to station Settlement Point, Grand Bahamas). In July and August 2012 the tidal range was likewise $50-90 \mathrm{~cm}$ and in late July 2012 water depths at low tide ranged between 80 and $130 \mathrm{~cm}$ at near-coast sampling sites along Graham Harbour (Table 1).

Grahams Harbour provides diverse habitats, e.g. patch reefs in the outer zone and seagrass meadows in the inner part (Beck, 1991; Wilson and Ramsook, 2007; Morgan and 


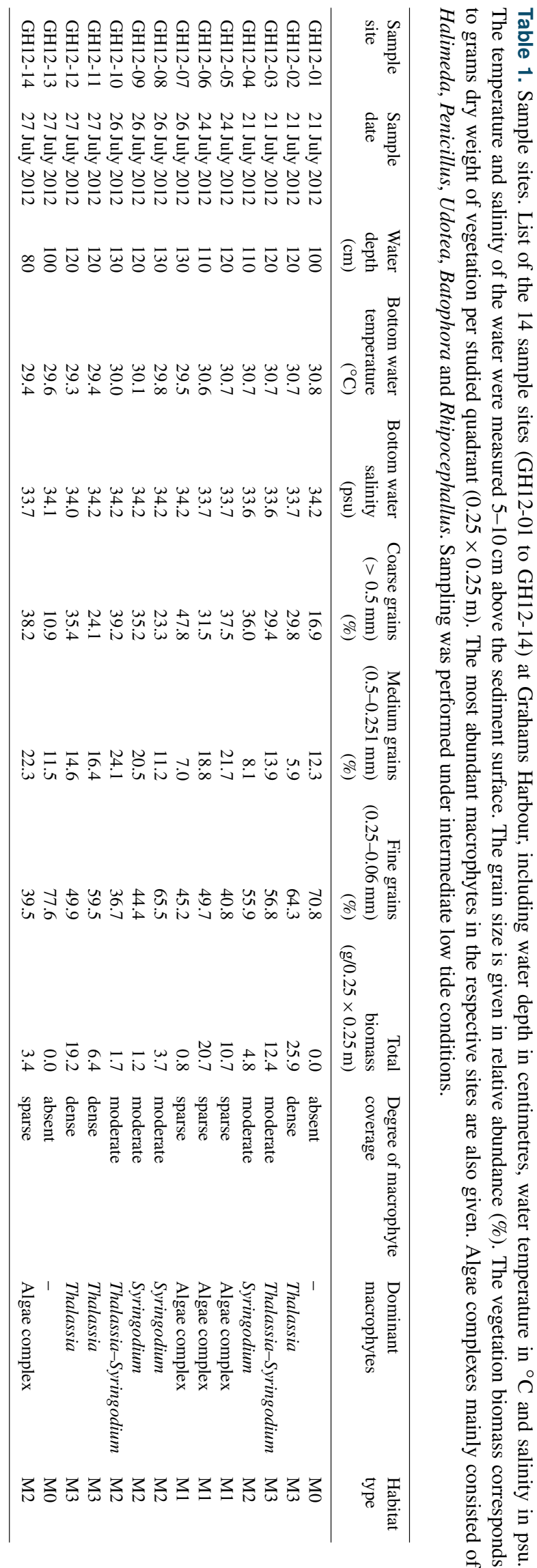

Lewis, 2010; Darroch et al., 2016). The relatively protected embayment forms an especially important habitat for seagrass meadows, ranging from patchy to dense and hosting a number of different macrophytes typical for the region, with an associated but fragile benthic microfauna (Gerace et al., 1998; Buchan, 2006; Morgan and Lewis, 2010; Darroch et al., 2016). The microhabitats within the studied transect vary from habitats subject to strong currents with sparse vegetation of Halimeda spp. and other macroalgae close to the Cut to environments with weak current activity and moderate to dense vegetation dominated by the seagrasses Thalassia testudinum and Syringodium filiforme along the coast (Fig. 1b).

\section{Material and methods}

\subsection{Sampling and material}

A $500 \mathrm{~m}$ long transect was sampled in July 2012 in a shallow lagoon along the shoreline of Grahams Harbour in the north of San Salvador, starting at the Old Dock $\left(24^{\circ} 7^{\prime} 23.50 \mathrm{~N}\right.$, $74^{\circ} 27^{\prime} 29.41 \mathrm{~W}$; sample station GH12-01) and terminating at the Cut $\left(24^{\circ} 7^{\prime} 39.72 \mathrm{~N}, 74^{\circ} 27^{\prime} 27.22 \mathrm{~W}\right.$; sample station GH12-14) (Figs. 1b, 2). The transect consists of 14 sample stations $40 \mathrm{~m}$ apart (Fig. 1b). Samples were taken while swimming with a snorkel using a small sealable beaker. At each station we collected one surface sediment sample (0$1 \mathrm{~cm}$ of sediment depth) used for foraminiferal analyses and one combined surface-subsurface sediment sample $(0-5 \mathrm{~cm}$ of sediment depth) for grain size analyses by scraping up the sediment using a plastic beaker. In addition, at each station we collected all marine macrophytes from the sea floor in an area of $0.25 \times 0.25 \mathrm{~m}$ (i.e. in one-quarter of the $0.50 \times 0.50 \mathrm{~m}$ frame used in sample collection). Samples were all taken in July 2012 during intermediate low tide conditions (neither spring nor neap tide) at water depths between 80 and $130 \mathrm{~cm}$ (Table 1, Fig. 1b). Water temperature and salinity at the sea floor at the time of sampling were measured to $29.3-30.8^{\circ}$ and 33.6-34.2 psu (Table 1), respectively, using a standard handheld salinity-conductivity-temperature meter.

Sediment samples mainly consist of carbonate grains. Grain size analysis was applied to the 14 sediment samples (upper $5 \mathrm{~cm}$ ) using wet sieving with mesh widths no. $12(1.5 \mathrm{~mm})$, no. $35(0.5 \mathrm{~mm})$, no. $60(0.25 \mathrm{~mm})$, no. 120 $(0.125 \mathrm{~mm})$ and no. $230(0.063 \mathrm{~mm})$. The relative proportion of each grain size fraction at each sample station was subsequently estimated based on the dry-weight fractions (Table 1). The average grain size was calculated and used as an index of the grain size distribution of each habitat. In lieu of actual current velocity measurements, energy settings and coastal current strength along the transect were estimated based on field observation and the proximity to the current inflow; current strength was highest at the Cut and weakening with increasing distance from the Cut, which is in accordance with the general hydrography (Gerace et al., 1998; Buchan and Lewis, 2009). Clay and silt contents were not 


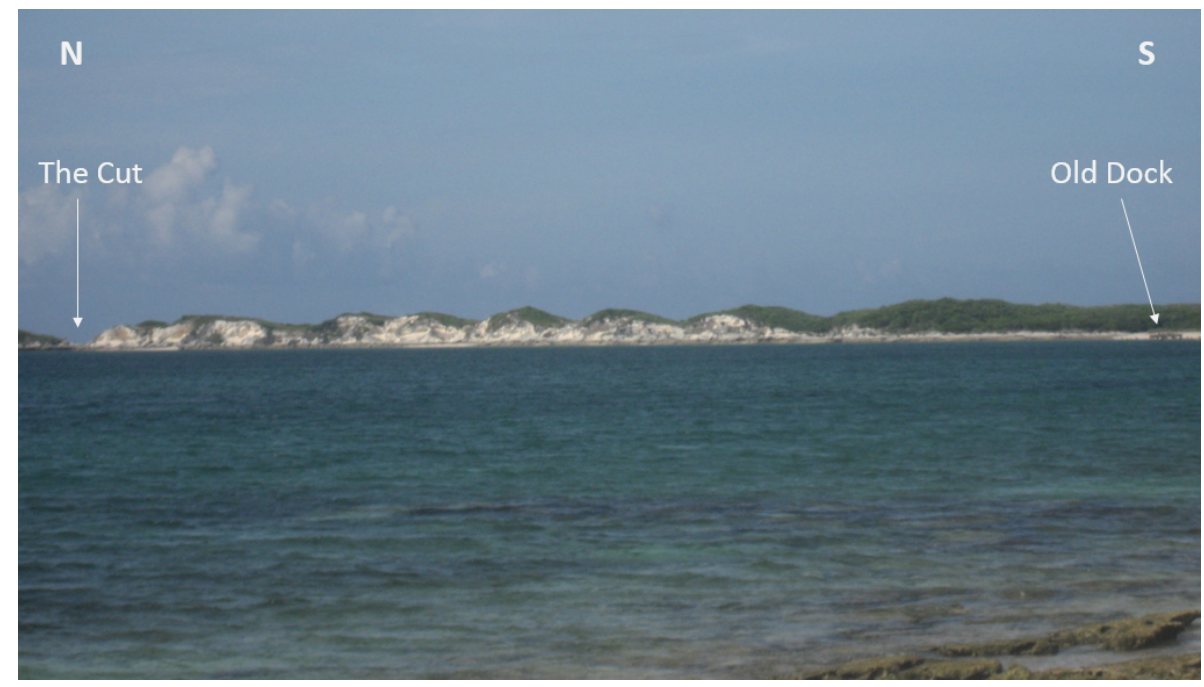

Figure 2. The Grahams Harbour section from Old Dock (start transect) to the Cut (end transect). Photo: Andrea Fischel, 2012.

investigated. Colby and Boardman (1989) reported that clay and silt were absent from recent sediments of Grahams Harbour. These grain sizes occur mainly in resuspension and accumulate further offshore, which was not part of the present study.

\subsection{Macrophyte identification and habitats}

Macrophyte taxa were identified following Littler et al. (1989) and Littler and Littler (2000) (Table 2). To determine the vegetation density (biomass) at each site, the marine macrophytes collected at each station were oven-dried $\left(40^{\circ} \mathrm{C}\right)$ and weighed after sampling (Table 2$)$. The macrophyte distribution is presented here both as a mass (grams of dry weight per quadrant) and as a percentage distribution. For this latter parameter, it must be kept in mind that some samples contain very low abundances of macrophytes with associated higher error of determination. In addition, some macrophytes were encrusted with calcium carbonate, which added to the biomass estimation. Based on the identification of the macrophytes in each sample combined with the visual inspection during sampling, each sample site was categorized into one of four microhabitats: M0 (vegetation absent), M1 (sparse vegetation), M2 (moderate vegetation) and M3 (dense vegetation).

\subsection{Laboratory treatment and analyses of foraminiferal samples}

The 14 surface $(0-1 \mathrm{~cm})$ sediment samples for foraminiferal analysis were treated with denatured ethanol (92\% ethanol mixed with seawater, resulting in an alcohol percentage of $60 \%-70 \%$ ) and rose-bengal staining (Walton, 1952) immediately after sampling. Although the number of living specimens was overall low, those specimens that were found to be alive showed a very clear staining, indicating a successful staining procedure. After staining for $24 \mathrm{~h}$, the surface samples were wet-sieved using no. $230(0.063 \mathrm{~mm})$ and no. $120(0.125 \mathrm{~mm}) \mathrm{mesh}$-size sieves and subsequently ovendried. The $>0.125 \mathrm{~mm}$ fraction was analysed for its dead (unstained) and living (stained) benthic foraminifera (Table 3) using a stereomicroscope Olympus SZ 3060. In total, a minimum of 200 dead specimens were counted for each sample site. Living foraminifera were registered separately in the same sample aliquot used for analysing the dead assemblage, but living specimens were only found in very low numbers. The taxonomy of Loeblich and Tappan (1988) as well as Darroch (2012) was used. Relative species abundances and absolute concentrations (tests per gram of surface sediment, i.e. test density) of the dead (thanatocoenosis) and living assemblage (biocoenosis) were calculated based on the weight of the analysed sediment (Table 3). The 0.063$0.125 \mathrm{~mm}$ fraction of the subsurface samples was also tested for its foraminiferal assemblage. However, as this fraction only contained relatively few foraminifera belonging to a restricted number of species, all of which were also present in the $>0.125 \mathrm{~mm}$ fraction, it was not studied further.

The foraminifera of the macrophyte samples from the 14 sites were analysed without applying rose-bengal staining. The foraminifera of the macrophyte samples were only identified to genus level. Each sample represents all macrophytes found in an area of $0.25 \times 0.25 \mathrm{~m}$ (one-quarter of the $0.5 \times 0.5 \mathrm{~m}$ quadrant used for foraminiferal and grain size analyses) at the vegetated sample sites.

\subsection{Classification of epiphytic foraminifera}

In order to compare the distribution of the (generally dead) epiphytic foraminifera in the surface sediment to the assemblages on the macrophytes, we calculated the relative abun- 


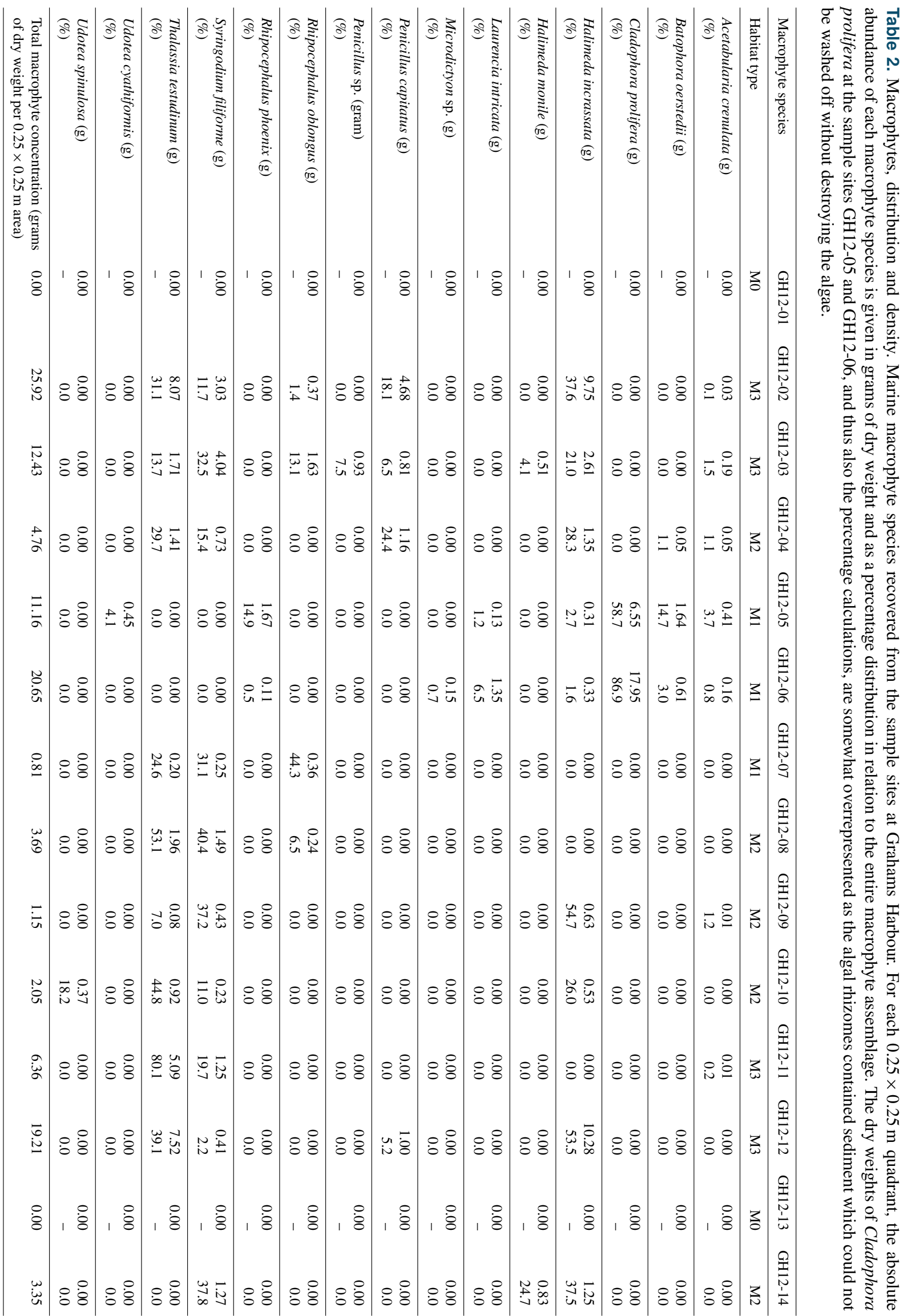




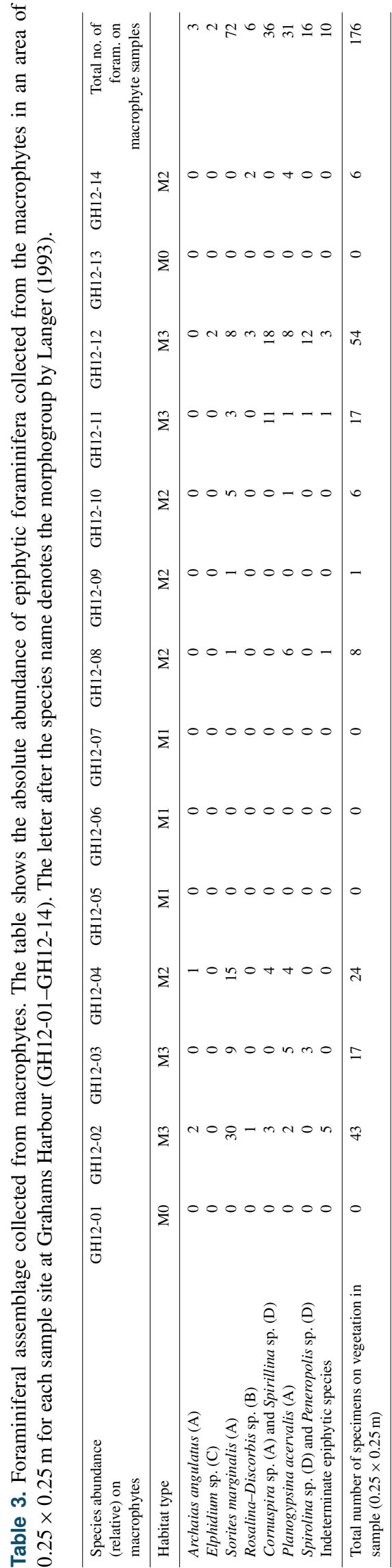

dance of sedimentary epiphytic foraminifera based on the total benthic faunal assemblage. All epiphytic foraminifera were collected from the macrophytes and identified; the occurrence of each species is reported as a percentage of the total number of epiphytic specimens collected in each sample. To specify the assemblage of epiphytic foraminifera, the classification based on morphotypes by Langer (1993) was applied: A, permanently attached foraminifera, e.g. planorbulinids and Sorites (morphotype A: flat concave test); B, temporarily attached foraminifera, e.g. Rosalina, Discorbis, and Asterigerina (morphotype B: trochospiral test); C, motile suspension-feeding foraminifera, e.g. elphidiids, (morphotype C: complex test structures with canal systems and multiple apertural openings); and D, permanently motile epiphytic species such as Quinqueloculina, Triloculina and Textularia (morphotype D: various test shape) (Table 4). This classification was applied in order to evaluate potential differences in the results related to the various morphotypes and their way of life (i.e. permanently attached vs. motile). In the present study, permanently to temporarily attached species (morphotypes A-C) were furthermore classified into the group epiphytic-type I, while epiphytic taxa with a permanently motile mode of life (morphotype D) were grouped as epiphytic-type II. These permanently motile epiphytictype II taxa are not limited to macrophyte habitats or even an attached way of life, in fact often living as epifaunal to shallow infaunal species on or in sediments substrates. Hence, it would not be possible to judge if a specimen of epiphytictype II found in the dead assemblage in the sediment in fact originally lived in the sediment or on macrophytes. Consequently, only epiphytic species that belong to epiphytictype I are included in our calculations.

In total, the following species are included in the epiphytic-type I group: Archaias angulatus (morphotype A), Asterigerina carinata (morphotype B), Cibicides spp. (B), Cibicidoides spp. (B), Discorbis rosea (B), Discorbis spp. (B), Cornuspira involvens (A), Cyclorbulina compressa (B), Cymbaloporetta bradyi (A), Cymbaloporetta squammosa (A), Elphidium spp. (morphotype C), Hauerina speciose (C), Osangularia culter (B), Parasorites spp. (A), Planogypsina acervalis (A), Rosalina floridana (B), Rosalina globularis (B), Rosalina subaraucana (B), Rosalina spp. (B) and Sorites marginalis (A).

\subsection{Multivariate statistics}

Ordination was applied to the dataset using the CANOCO v4.5 software package (ter Braak and Šmilauer, 2002). An initial detrended correspondence analysis (DCA) on foraminiferal percentage data gave (irrespective of transformation methods) gradient lengths of DCA axis 1 of the total dead assemblage below 2, indicating that linear models (e.g. PCA, RDA) are appropriate for the ordinations. Due to a high number of different epiphytic-type I species in the fossil assemblage $\left(n_{\text {epi }}=21\right)$ compared to the limited 


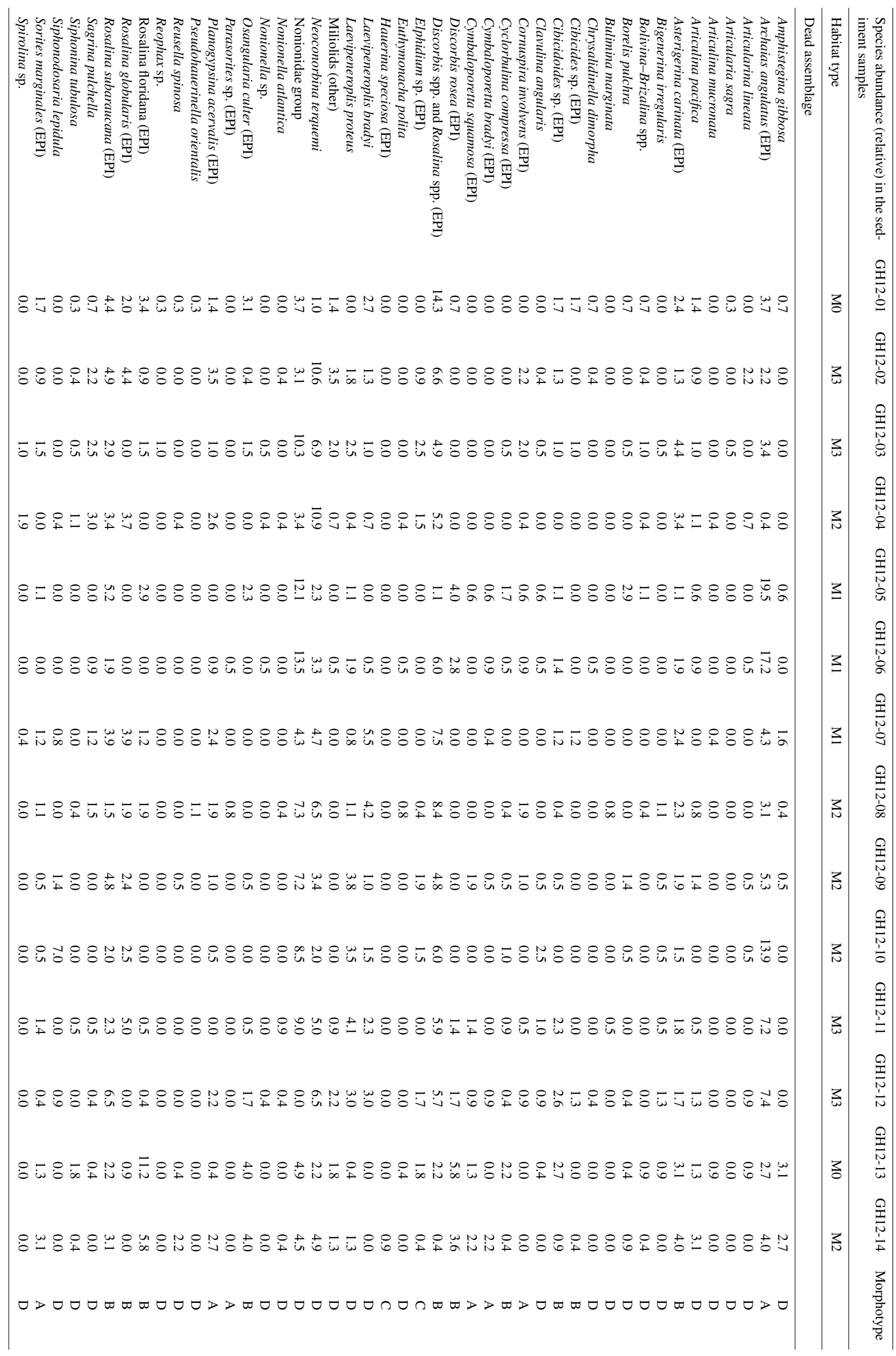




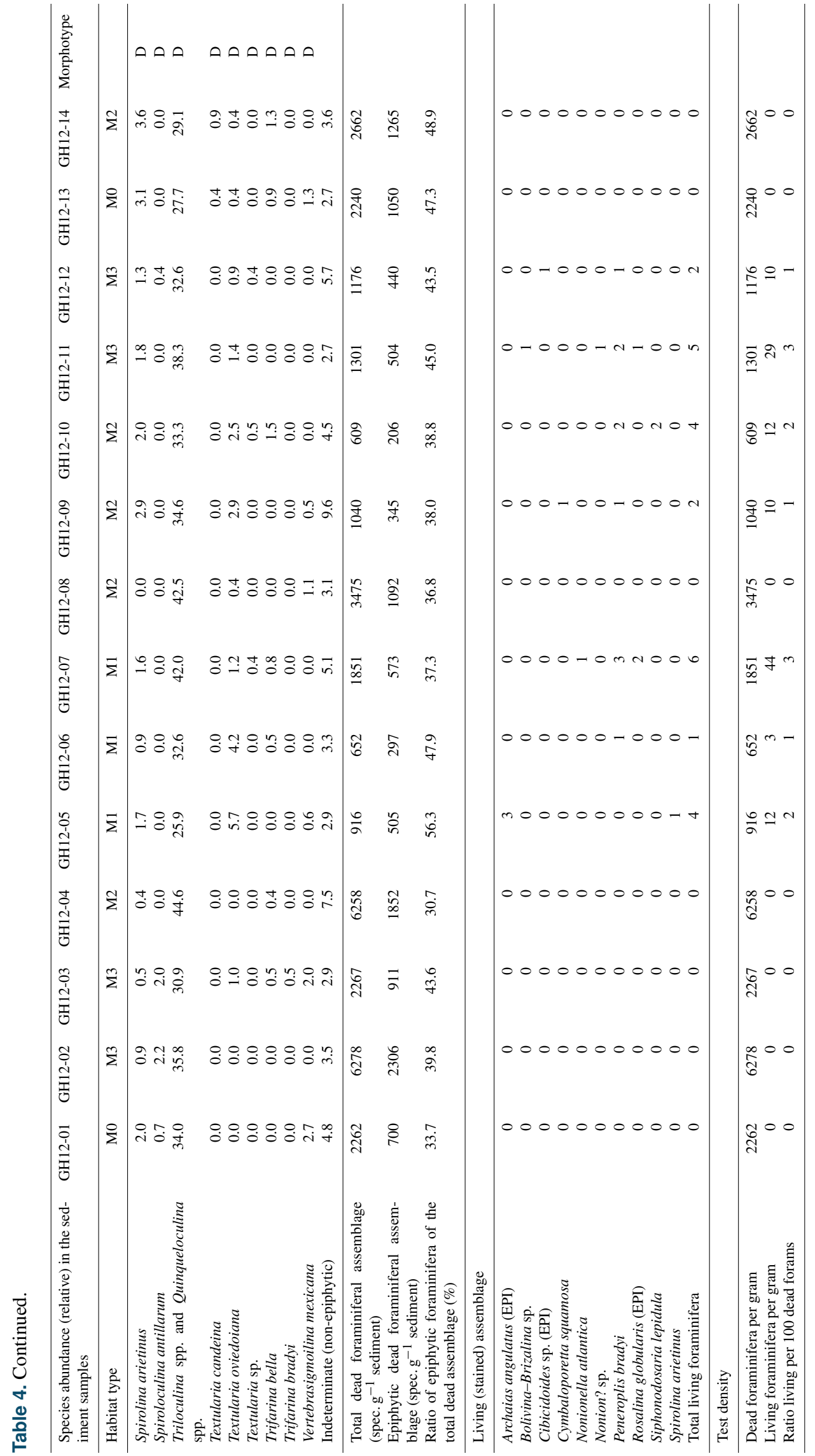


Table 5. List of benthic foraminiferal species and author names encountered in the biocoenosis and thanatocoenosis in surface sediments and on macrophytes from Grahams Harbour, San Salvador Island.

\begin{tabular}{|c|c|}
\hline Benthic foraminiferal taxon-group & $\begin{array}{l}\text { Author and year of original de- } \\
\text { scription }\end{array}$ \\
\hline Amphistegina lessonii & d'Orbigny 1826 \\
\hline Archaias angulatus & (Fichtel and Moll 1789) \\
\hline Articularia lineata & (Brady 1884) \\
\hline Articularia sagra & (d'Orbigny 1839) \\
\hline Articulina mucronata & d'Orbigny 1839 \\
\hline Articulina pacifica & Cushman 1944 \\
\hline Asterigerina carinata & d’Orbigny 1839 \\
\hline Bigenerina irregularis & Phleger \& Parker 1951 \\
\hline \multicolumn{2}{|l|}{ Bolivina spp. } \\
\hline Borelis pulchra & Cushman 1930 \\
\hline \multicolumn{2}{|l|}{ Brizalina spp. } \\
\hline Bulimina marginata & d'Orbigny 1826 \\
\hline Chrysalidinella dimorpha & Brady 1881 \\
\hline \multicolumn{2}{|l|}{ Cibicides spp. } \\
\hline \multicolumn{2}{|l|}{ Cibicidoides spp. } \\
\hline Clavulina angularis & d'Orbigny 1826 \\
\hline Cornuspira involvens & Reuss 1850 \\
\hline Cyclorbulina compressa & d'Orbigny 1839 \\
\hline Cymbaloporetta bradyi & Cushman 1924 \\
\hline Cymbaloporetta squammosa & d'Orbigny 1826 \\
\hline Discorbis rosea & d'Orbigny 1839 \\
\hline \multicolumn{2}{|l|}{ Discorbis spp. } \\
\hline \multicolumn{2}{|l|}{ Elphidium spp. } \\
\hline Hauerina speciosa & Reuss 1856 \\
\hline Laevipeneroplis bradyi & (Cushman 1930) \\
\hline Laevipeneroplis proteus & (d'Orbigny 1839) \\
\hline \multicolumn{2}{|l|}{ Miliolidae } \\
\hline Euthymonacha polita & (Chapman 1900) \\
\hline Neoconorbina terquemi & (Rzehak, 1888) \\
\hline \multicolumn{2}{|l|}{ Nonion spp. } \\
\hline Nonionella atlantica & Cushman 1947 \\
\hline \multicolumn{2}{|l|}{ Nonionella spp. } \\
\hline Osangularia culter & (Parker and Jones 1865) \\
\hline \multicolumn{2}{|l|}{ Parasorites spp. } \\
\hline Planogypsina acervalis & (Brady 1884) \\
\hline Pseudohauerinella orientalis & Cushman 1946 \\
\hline \multicolumn{2}{|l|}{ Quinqueloculina spp. } \\
\hline Reusella spinulosa & Cushman 1947 \\
\hline \multicolumn{2}{|l|}{ Reophax spp. } \\
\hline Rosalina floridana & (Cushman 1922) \\
\hline Rosalina globularis & d' Orbigny 1826 \\
\hline \multicolumn{2}{|l|}{ Rosalina spp. } \\
\hline Rosalina subaraucana & Cushman 1922 \\
\hline Sagrina pulchella & d' Orbigny 1839 \\
\hline Siphonina tubulosa & Cushman 1924 \\
\hline Siphonodosaria lepidula & (Schwager, 1866) \\
\hline Sorites marginalis & (Lamarck 1816) \\
\hline \multicolumn{2}{|l|}{ Spirillina spp. } \\
\hline Spirolina arietinus & (Batsch 1791) \\
\hline Spiroloculina antillarum & d'Orbigny 1839 \\
\hline Textularia candeina & d'Orbigny 1839 \\
\hline Textularia oviedoiana & (d’Orbigny 1839) \\
\hline \multicolumn{2}{|l|}{ Textularia spp. } \\
\hline Trifarina bella & (Phleger and Parker 1951) \\
\hline Trifarina bradyi & Cushman 1923 \\
\hline \multicolumn{2}{|l|}{ Triloculina spp. } \\
\hline Vertebrasigmoilina mexicana & Cushman 1922 \\
\hline
\end{tabular}

number of samples $(n=14)$, a principal component analysis (PCA) was used to reduce the dimensionality to four main axes. Subsequently, the relationship between the axis (species) scores and environmental factors was assessed using a series of redundancy analyses (RDA) with associated Bonferroni-adjusted Monte Carlo permutation tests of significance $(n=999)$.

\section{Results}

\subsection{Living foraminiferal assemblages attached on macrophytes}

The in situ living foraminiferal assemblages found attached to the macrophytes were studied in the different habitats of Grahams Harbour. In total, five genera were identified, encompassing at least 15 species (Tables 3, 5). Sorites marginalis (morphotype A) was the most abundant species, dominating the assemblages in the habitats distal from the tidal inflow (M2, M3 habitats), as also previously described by Buchnan and Lewis (2009) from Grahams Harbour. In contrast, the Rosalina-Discorbis group (morphotype B) dominated the assemblage proximal to the current inflow at the Cut (site GH12-14; M1 habitat). Spirulina sp., Elphidium sp. and Cornuspira sp. (morphotypes D, C and A, respectively) have the highest abundances in the ThalassiaSyringodium habitats (M3) of intermediate energy setting (sites GH12-11 and GH12-12). The remaining species found in habitats M1-M3 were only found in low abundances.

Despite the limited number of sample points making the comparison uncertain, maximum epiphytic species diversities seem to be linked to Thalassia habitats (M3). Here seven different taxa were registered. Lower diversities among epiphytic foraminifera occur in assemblages collected from $S y$ ringodium and macroalgae habitats (M2), where only three taxa were observed. Also, population densities were highest in connection to the Thalassia-Syringodium community with 172-216 specimens in an area of $0.25 \times 0.25 \mathrm{~m}$ in contrast to 4-24 specimens observed on calcareous macroalgae substrate (e.g. Halimeda, Penicillus) in a similar area size. Multivariate analyses were not applied to the living assemblage due to the quantitative limitation of the dataset.

\subsection{Foraminiferal assemblages in surface sediments}

In total, 56 different benthic foraminiferal taxa were identified in the dead assemblages, whereas 8 taxa were found in the living community of the surface sediments (Tables 4 , 5). The dead foraminiferal assemblages (thanatocoenoses) were dominated by Triloculina spp. and Quinqueloculina spp. (morphotype D) each with $35 \%-45 \%$ relative abundance. Other common taxa were Discorbis spp. and Rosalina spp., whereas Nonionidae (D), Neoconorbina terquemi (D) and Archaias angulatus (A) were observed in lower numbers. 
Quantitative analyses showed only low numbers of living foraminifera (biocoenosis) in the sediment. Four sample sites (GH12-05, GH12-06, GH12-09, GH12-12) contained one to three living specimens in the analysed material, while sites GH12-07, GH12-10 and GH12-11 held four to six living specimens, with the majority of the specimens belonging to Peneroplis sp. (morphotype D) (Table 4). Seven out of the 14 stations contained no living benthic foraminifera.

The test densities of the dead assemblage varied between 609 and 6258 specimens per gram (spec. $\mathrm{g}^{-1}$ ) of surface sediment (Table 4), with foraminiferal tests on average making up ca. $5 \%$ of all grains in the $>0.125 \mathrm{~mm}$ sediment fraction. The highest abundance of dead foraminiferal tests (>6200 spec. $\mathrm{g}^{-1}$ ) was observed in sample sites with moderate to dense vegetation located distally from the tidal inflow (GH12-02 and GH12-04), whereas relatively low test densities, approximately 600-900 spec. $\mathrm{g}^{-1}$, occurred in areas with sparse vegetation and a solid carbonate bedrock underlying the few-centimetres-thin unconsolidated surface sediments (GH12-05, GH12-06 and GH12-10). Closer to the tidal inflow (GH12-11 to GH12-14) where current energy is higher, test densities varied between 1100 and 2600 spec. $\mathrm{g}^{-1}$. The estimates of test density of the living assemblages have a high sample error but seem to follow a pattern inverse to the dead assemblages. Here the highest densities of 29-44 spec. $\mathrm{g}^{-1}$ were recorded in sparsely to moderately vegetated areas (GH12-07 and GH12-11) (Table 4). Remarkably, the highest abundances of living foraminifera were concentrated in the middle part of the transect, including the stations $\mathrm{GH} 12-05$ to $\mathrm{GH} 12-12$. In close proximity (stations GH12-13, GH12-14) and further distal to the tidal inflow (stations GH12-01 to GH12-05) living foraminifera seemed to be absent (or abundance is extremely low, as it could not be registered in the present study). One to three living foraminifera per 100 dead specimens were observed at the sample sites which contained foraminifera (Table 4).

\subsection{Microhabitat classification of foraminiferal sedimentary thanatocoenosis}

Of the 56 taxa in the dead assemblages (thanatocoenoses) of the surface sediment samples (Table 4), 21 were epiphytic taxa (epiphytic-type I+ II). Specimens were overall well preserved, including the smaller, more fragile taxa such as Nonionidae. The epiphytic-type I group in the foraminiferal thanatocoenoses was dominated by Archaias angulatus (morphotype A), the Rosalina-Discorbis group (e.g. Rosalina floridana, Rosalina subaraucana and Discorbis rosea; all B), Laevipeneroplis proteus (D) and Laevipeneroplis bradyi (D). To specify the foraminiferal abundance in the dataset, the foraminiferal assemblages were classified with respect to the four microhabitats (M0, M1, M2, M3) distinguished based on the macrophyte vegetation in each habitat. The density of macrophytes per $\mathrm{m}^{2}$ was also taken into account (Figs. 3, 4, 5, Table 1).
- Microhabitat M0 is defined as areas lacking marine macrophytes and is found at sample stations GH1201 and GH12-13 (Fig. 1b). The grain size distribution in these habitats is highly homogeneous and fine grains $(<0.25 \mathrm{~mm})$ make up more than $70 \%$ of the sediment. Epiphytic-type I foraminifera (dominantly the Rosalina-Discorbis group B) encompass 34\%-47\% of the thanatocoenoses (Fig. 4, Table 4).

- Microhabitat M1 (stations GH12-05 to GH12-07) is characterized by sparse vegetation, primarily inhabited by calcareous algae, mainly Cladophora, Acetabularia, Laurentia and Batophora. The grain size distribution appears broader than for M0, with a high fraction of coarse grains. Epiphytic (type I) foraminifera (dominated by Archaias angulatus (A) and the RosalinaDiscorbis group B) are abundant, encompassing 37\%$56 \%$ of the total dead benthic foraminiferal assemblages (Table 4). They increase in abundance towards the tidal inflow (the Cut).

- Microhabitat M2 is characterized by moderate vegetation, mainly of Syringodium filiforme and various calcareous algae, e.g. Halimeda, Rhipocephalus and Udotea, but also some Thalassia reaching a vegetation biomass density of 5-20 $\mathrm{g} \mathrm{m}^{-2}$ (sample sites GH12-04, GH12-08, GH12-09, GH12-10 and GH12-14; Figs. 1b, 3 , Table 2). The epiphytic-type I foraminiferal abundance in the dead assemblages is lowest in M2 habitats (30\%-38\%), dominated by the Rosalina-Discorbis group (B) and by Archaias angulatus (A) (Table 4). In general, total test densities of dead foraminifera in M2 habitats vary by a factor of 10 (i.e. 6260 specimens $\mathrm{g}^{-1}$ sediment distal to the tidal inflow at site GH12-04 and 610 specimens $\mathrm{g}^{-1}$ sediment proximal to the tidal inflow at site GH12-10).

- Microhabitat M3 is dominated by Thalassia testudinum and Syringodium filiforme (stations GH12-02, GH1203, GH12-11 and GH12-12; Figs. 1b, 3b), forming dense seagrass beds with a high vegetation biomass $\left(25-100 \mathrm{~g} \mathrm{~m}^{-2}\right)$. The total dead foraminiferal test density decreases towards the tidal opening, similar to M2 habitats. The proportion of epiphytic (type I) foraminifera varies between $40 \%$ and $45 \%$ of the total dead fauna, decreasing towards the tidal opening and being dominated by the Rosalina-Discorbis group (B) and Archaias angulatus (A) (Table 4).

\subsection{Multivariate analyses of the thanatocoenosis}

PCA axes 1-4 together account for $82.7 \%$ of the variation of the dead foraminiferal assemblages. Taxa with high scores on PCA axis 1 (PCA-AX1, eigenvalue: $44.8 \%$ ) include the species Archaias angulatus (+0.84), Textularia oviedoiana $(+0.82)$ and Cyclorbiculina compressa 

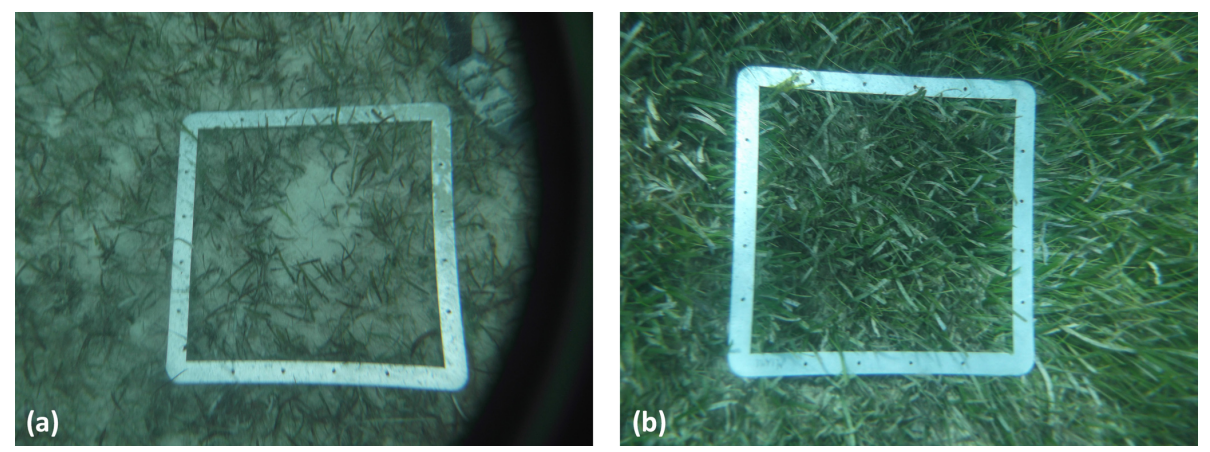

Figure 3. Examples of sea-floor vegetation also showing the metal frame used during sampling. (a) Sparsely to moderately vegetated area typical for an M2 vegetation habitat, with a mix of calcareous algae and some seagrass (Thalassia). (b) Densely vegetated sea floor covered by seagrass typical for an M3 habitat. Photo: Sonja Reich, 2012.

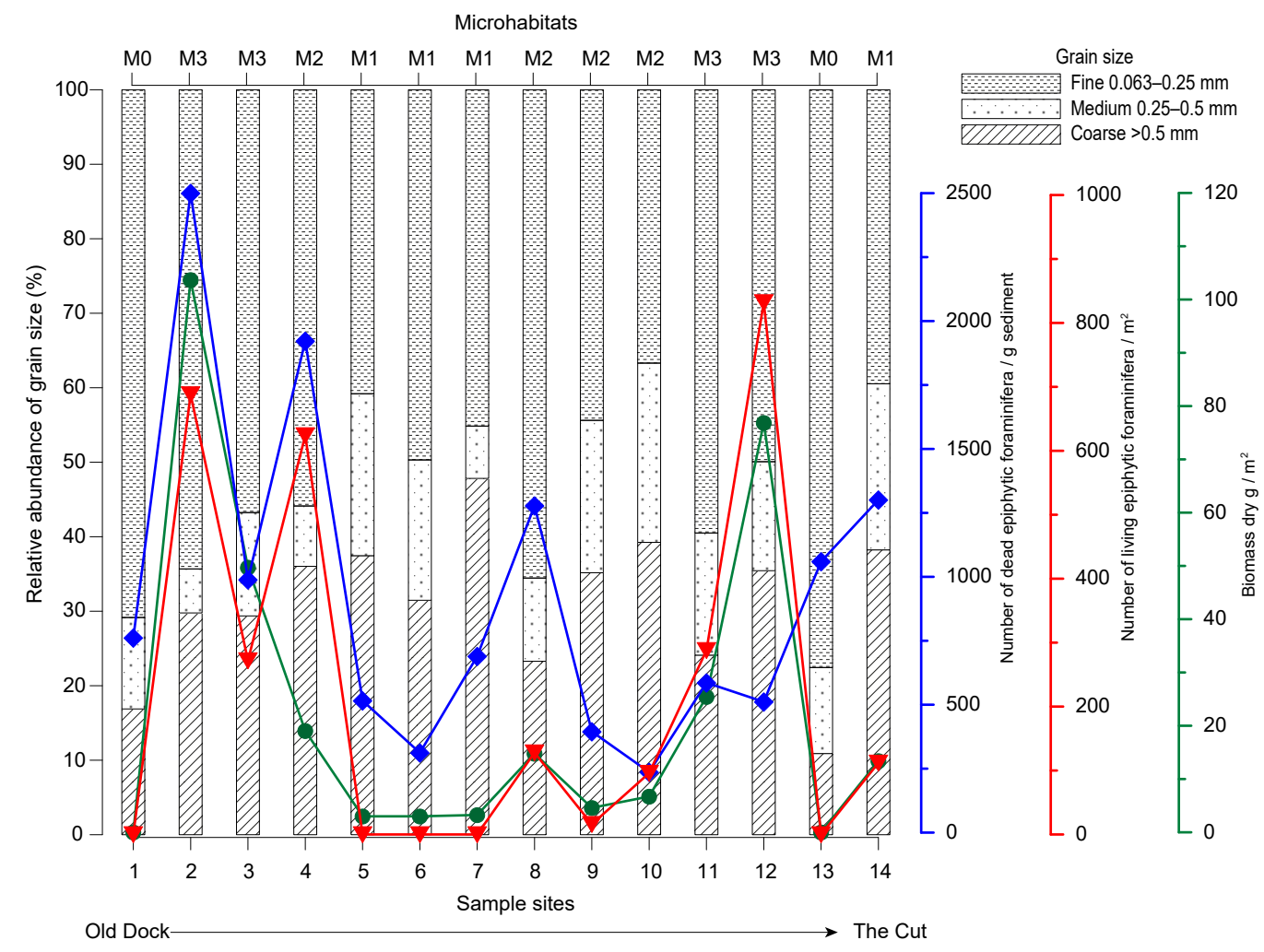

Figure 4. Graph showing physical and biological proxies (grain size, macrophyte biomass, and the number of living and dead epiphytic foraminifera) recorded at each sample site. The cumulative relative percentage of the grain size fractions is shown as a bar chart (dashed column: grains less than $0.25 \mathrm{~mm}$ in diameter; dotted column: grain sizes between 0.25 and $0.5 \mathrm{~mm}$; hatched column: grains larger than $0.5 \mathrm{~mm}$ ). Macrophyte biomass, indicated by the green curve (green circles), is given in grams of dry biomass per $\mathrm{m}^{2}$. The distribution of epiphytic foraminifera is plotted as the number of specimens in the dead assemblage per gram of dry surface sediment (blue curve, blue diamonds). The number of specimens in the living assemblage per $\mathrm{m}^{2}$ of vegetated area is shown in the red curve (red triangles). The curves show a subjective interpolation between the sample sites. The microhabitat index M0 for areas with no vegetation; areas with sparse vegetation, mainly calcareous macroalgae (M1); habitats with moderate vegetation of Syringodium-algae complexes (M2); and dense seagrass beds dominated by Thalassia and Syringodium (M3).

$(+0.68)$. In contrast, the following taxa show low scores: Triloculina-Quinqueloculina sp. (-0.84), Planogypsina acervalis (-0.67), Neoconorbina terquemi $(-0.66)$ and Ros- alina spp. (-0.64). This suggests that PCA axis 1 can be seen as reflecting morphological variations from large ( $>400 \mu \mathrm{m}$ ), compressed species (positive score) to smaller, 


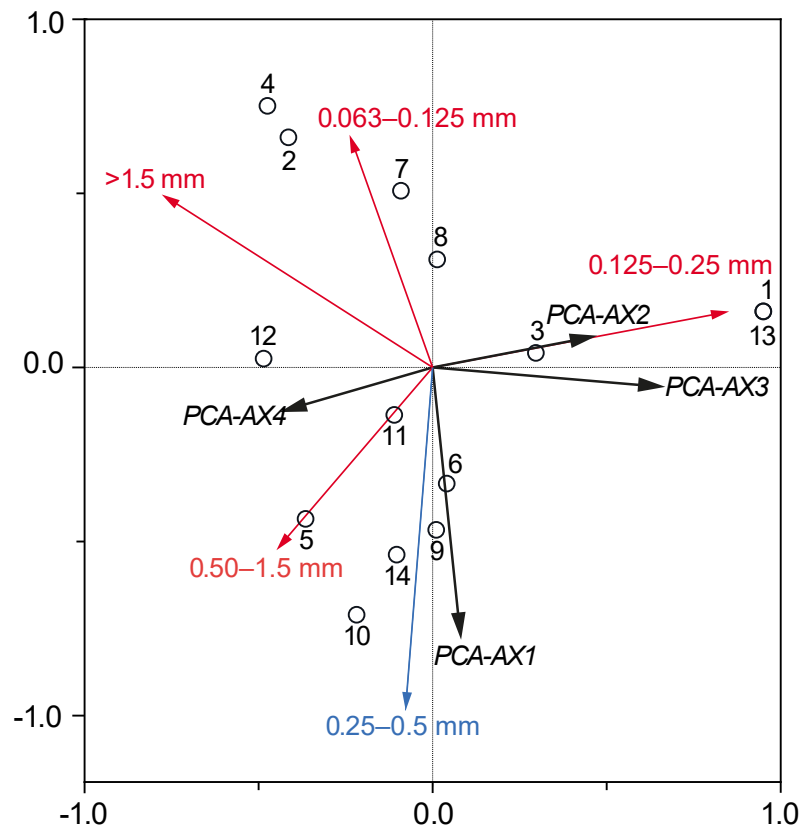

Figure 5. RDA plot showing the total foraminiferal thanatocoenosis against grain size. Sample sites are indicated by a black circle as well as by site number (GH12-01 to GH12-14). Sample sites 1 and 13 showed identical scoring. The foraminiferal fauna is statistically divided into four PCA axes (PCA-AX1, PCA-AX2, PCA-AX3 and PCA-AX4) illustrated as black vectors. Grain size fractions in millimetres are shown as red and blue vectors; only the $0.25-0.5 \mathrm{~mm}$ fraction (shown as the blue vector) was significant for the faunal variation in the foraminiferal thanatocoenosis.

more rounded tests (negative score). PCA axis 2 (PCA-AX2, eigenvalue: $22.9 \%$ ) seems to reflect a second morphological feature, with species with a convex test shape scoring positively (Osangularia culter with +0.879 , Rosalina floridana with +0.85 and Amphistegina gibbosa with +0.76 ), while species with a more compressed or elongated test shape score negatively (Archaias angulatus with -0.49 , Nonionidae with -0.46 and Textularia oviedoiana with -0.47 ). PCA axes 3 and 4 (PCA-AX3, eigenvalue: $8.2 \%$; PCA-AX4, eigenvalue: $6.8 \%$ ) are less easy to interpret as no common morphological features or ecological preferences can be defined for the species with high and low scores along these axes.

RDA with forward selection and a Monte Carlo permutation test $(n=999)$ of the foraminiferal PCA axes against grain size distributions shows that the particle size $0.25-$ $0.5 \mathrm{~mm}$ explains a significant proportion $(16 \%, p<0.05)$ of the foraminiferal variation represented by the four PCA axes (Fig. 5). This analysis also identifies the grain size $>1.5 \mathrm{~mm}$ as important $(p<0.05)$, but scatter plots show that this correlation depends on a single extreme sample. Accordingly, the apparent correlation with $>1.5 \mathrm{~mm}$ grains is disregarded here. In contrast, the importance of the $0.25-0.50 \mathrm{~mm}$ grain size fraction is supported by the fact that the sum of per-

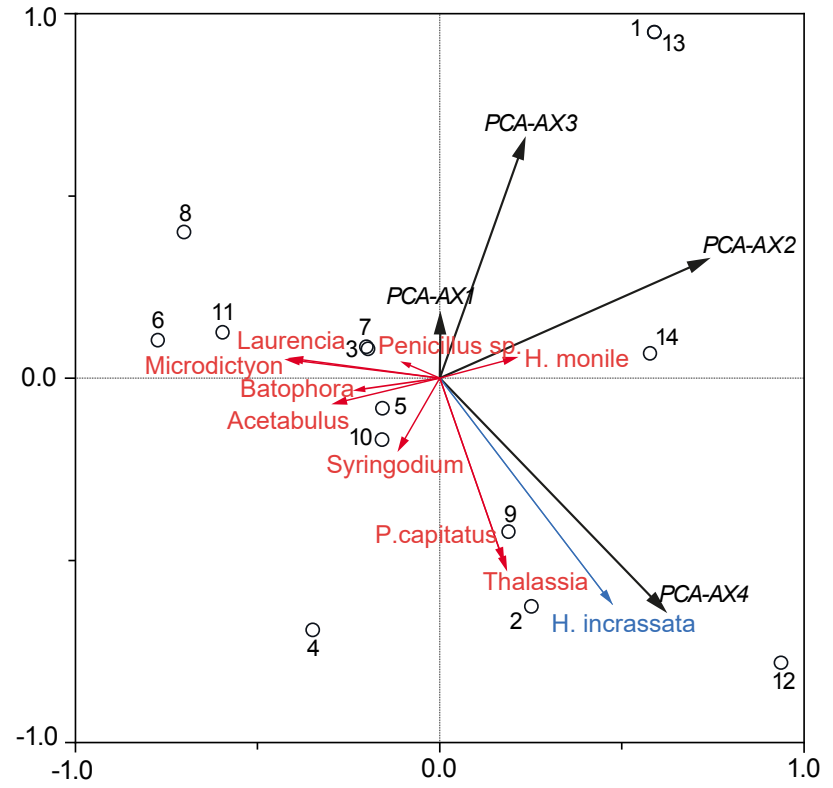

Figure 6. Partial RDA plot demonstrating the total sedimentary foraminiferal assemblage against the absolute macrophyte biomass, including the $0.25-0.5 \mathrm{~mm}$ grain size fraction as a co-variable. Black circles show each of the sample sites (GH12-01 to GH1214), with sample sites GH12-01 and GH12-13 showing identical scores. The black vectors comprise four PCA axes (PCA-AX1 to PCA-AX4), covering all species of the thanatocoenosis. The most abundant macrophyte species are shown as red and blue vectors. Exclusively the macrophyte species $H$. incrassata (singled out as the blue vector) was statistically significant for the faunal variability of the total foraminiferal thanatocoenosis.

centages of foraminifera larger than $1 \mathrm{~mm}$ in diameter shows a clear positive relationship with exactly this grain size fraction. Since foraminifera generally make up $\sim 5 \%$ of this sediment fraction it is unlikely that the correlation is an artefact of the increasing test size itself, supporting the fact that this correlation is reliable.

A partial RDA with the $0.25-0.5 \mathrm{~mm}$ grain size as a covariable was run against macrophyte relative frequencies. The purpose was to explore if macrophyte biomass or cover pattern could explain a significant part of the residual variation (after accounting for the variation explained by grain size) (Fig. 6). Variations in the density distribution of $\mathrm{Hal}$ imeda incrassata explain $16 \%(\mathrm{p}<0.05)$ of the residual foraminiferal variation, while no other single macrophyte taxon gave any significant contribution. Similarly, a partial RDA (co-variable: $0.25-0.5 \mathrm{~mm}$ ) against biomass (absolute and in percentage) showed only Halimeda incrassata to be significantly related to the total foraminiferal assemblage (explanatory power $17 \%, p<0.05$ ). An RDA of macrophyte biomass against grain size showed no significant relationship. When testing the faunal variation in the epiphytictype I foraminiferal dead assemblage only, PCA axes 1-4 accounted for a total of $87.2 \%$ of the variance. No further sig- 
nificant relationships were found when comparing the sample score of these PCA axes in a series of RDAs with sediment grain size, absolute biomass and percentage of biomass.

\section{Discussion}

\subsection{Environmental control of the biocoenoses and thanatocoenoses}

The relative abundances of dead epiphytic (type I) foraminifera, excluding the permanently motile epiphytic (type II) species (Langer, 1993) range between $31 \%$ and $56 \%$ in the thanatocoenoses at Grahams Harbour. Similar to findings of previous studies (Brasier, 1975; Wilson and Ramsook, 2007; Wilson, 2010), a large part of the foraminiferal community is adapted to the nutrient-depleted conditions of surface sediments in Caribbean nearshore environments by living attached to the leaves and rhizomes of macrophytes. The generally low abundance of direct predators (predation on foraminifera) in nearshore waters in the Caribbean (Lipps, 1983 , 1988) combined with a very low indirect predation, e.g. grazing of the macroalgae and seagrasses by sea turtles and manatees (Jackson et al., 2001), enables epiphytic foraminifera to colonize exposed macrophytes. Foraminifera are not only restricted to macrophyte rhizomes, as they are also found on the thalli of species of e.g. Halimeda, Penicillus and Udotea and on the leaves of Thalassia and Syringodium. Thus, the abundance of epiphytic foraminifera in the foraminiferal community is very high compared to extratropical realms. A large proportion of the epiphytic foraminifera included in our study represents group A and $B$ of Langer's classification, including the permanently attached (group A) and temporarily attached species (group B). Both groups are characterized by a flat orbitoidal to discoidal shape (e.g. Loeblich and Tappan, 1988; Langer, 1993).

Abundance patterns of living and dead foraminifera at Grahams Harbour demonstrated differences between habitats with variance in macrophyte coverage. This is especially clear for the thanatocoenoses, for which test densities varied between 250 and 2500 specimens $\mathrm{g}^{-1}$ surface sediment. The lowest test concentrations were observed in habitats with sparse vegetation of calcareous macroalgae in a low-currentenergy regime, but also in areas with dense vegetation in a high-current regime. The highest test densities were observed in habitats with dense to moderate vegetation dominated by Thalassia and Syringodium in low-current environments. All epiphytic morphotypes (A-D; Langer, 1993) were present on the macrophytes and in the thanatocoenoses (Tables 3,4), albeit with the sediment biocoenosis dominated by living morphotype D species. However, the number of specimens was too low to reliably test for any link between habitat (M0-M3) and morphotypes.

The canonical ordination results of the dead foraminifera found in surface sediments clearly show that the main patterns of distribution are linked to grain size and hence to sedimentary processes (see below). However, after the foraminiferal variation correlated with sediment grain size was separated out statistically, a small part of the residual variation could successfully be related to variations in the density of one species of plant macrophyte, namely Halimeda incrassata. The lack of correlation between grain sizes and macrophyte distribution furthermore suggests that sedimentary processes had little significance for macrophyte cover patterns. This finding is somewhat unexpected, but an explanation may be sought in the relatively limited environmental gradient along the sampled coastline.

\subsection{Sedimentation and current control of foraminiferal habitats}

Quantitative analyses of the surface sediments of Grahams Harbour show a high but variable abundance of dead foraminifera in the top sediment. The RDA results of the dead foraminiferal assemblages suggest that a large proportion of the assemblage variation cannot be accounted for by any of the environmental factors recorded in our study. However, the correlation between the main gradient of foraminiferal assemblages (PCA-AX1) and the $0.25-0.5 \mathrm{~mm}$ grain size fraction (Fig. 5), apparently governed by the relationship between larger tests of foraminifera and the same grain size fraction, clearly suggests that sedimentary processes, i.e. transport of dead foraminiferal tests as part of the sediment fraction, play a very important role for the thanatocoenoses. The pattern of maximum concentration of empty tests in habitats with moderate to dense macrophytal coverage distal from the tidal inflow, with relatively low concentrations in areas with a higher-energy regime, is also likely a function of sedimentation processes. As previously described from the Bahamas regions (Winland and Matthews, 1974; Hine et al., 1981; Park, 2012), sedimentation processes are highly affected by tidal currents and wave and wind action. Areas with the highest test densities may thus be assumed to represent accumulation areas linked to lower current velocities and less impact from winds due to the distance to the tidal inflow and with the presence of dense seagrass meadows acting as sediment traps. In contrast, abrasion and resuspension in a higher-energy regime likely dominate areas with a low dead foraminiferal density, most prominent at sites close to the tidal inflow and areas with solid bedrock in the subsurface. Such an overprint of the autochthonous foraminiferal thanatocoenosis is often governed by post-mortem lateral transport and energy-controlled facies mixing (Ginsburg and Lowenstam, 1958; Taylor and Lewis, 1970; Miller, 1988). A similar distribution pattern was observed in a sedimentological study in the same area (Colby and Boardman, 1989).

In contrast, Martin and Wright (1988) in a study off Florida found little impact of sediment processes on the thanatocoenosis, instead linking the differences between the biocoenosis and the thanatocoenosis to different postmortem test preservation in different species. As the dead 
specimens in our study were overall well preserved, including the smaller more fragile taxa, we cannot confirm significant post-mortem test preservation as the main cause for the differences between the living epiphytic assemblages on the macrophytes and the dead assemblage in the sediment. However, we also cannot rule out that differential preservation plays some role, as Buchan and Lewis (2009) and Darroch et al. (2016) have in fact described some degradation, especially in dead Archaias angulatus from Grahams Harbour. Furthermore, the near absence of Sorites marginalis in the thanatocoenosis, despite it being the dominant species living on the macroalgae, indeed supports the conclusion that test degradation may also play a role (see Martin and Wright, 1988; Buchan and Lewis, 2009).

The accumulation of foraminiferal tests in nearshore environments is generally believed to be macrophyte dependent, though sediment mixing occurs through lateral transport linked to energy-controlled processes, e.g. tidal currents or longshore currents (Ginsburg and Lowenstam, 1958; Taylor and Lewis, 1970; Miller, 1988). A secondary shift in the grain matrix may also occur due to tropical storms and hurricanes hitting the Bahamian archipelago annually with maximum intensities in September-October (Colby and Boardman, 1989; Park, 2012).

Swinchatt (1965) and Scoffin (1970) suggested that the macrophyte cover determines the depositional environment in shallow bays of the Bahamian islands as it tends to control the sorting and sediment deposition. It would thus cause a reduction in grain size in habitats with dense macrophyte cover, e.g. in connection to Thalassia mats. Although fine sand made up a major component of the sediment in our study area, a relatively higher abundance of coarser grains was in fact found in the surface sediment of Thalassiadominated habitats. Our findings are thus in accordance with those of Colby and Boardman (1989) that coarse grains were more abundant in the Thalassia-vegetated areas of Grahams Harbour. It thus supports the interpretation that sedimentation patterns, and consequently post-mortem transport of foraminiferal tests, is governed by strong lateral sediment transport caused by longshore currents, although the influence of strong storms and hurricanes cannot be excluded. This conclusion is further supported by the fact that in our study dead epiphytic foraminifera were also abundant at locations without any macrophytes. Thus although plant cover does play a role for the dead assemblages, this factor is largely overprinted by the consequences of sediment transport (see also Winland and Matthews, 1974; Hine et al., 1981).

Living foraminifera were only found in low abundances in the surface sediments and a relatively richer living foraminiferal assemblage was only found in the epiphytic foraminiferal community attached to macrophytes at these sites (Table 3; see also discussion below). The overall very low abundance of living foraminifera in the surface sediments at Grahams Harbour is in agreement with earlier re- ports in oligotrophic nearshore sediments in the Caribbean of a general scarcity of living foraminifera, the majority of which adopt an epiphytic life style (Langer, 1993; Wilson, 1998; Wilson and Ramsock, 2007). Due to this limited amount of data on living foraminifera in the present study, a more precise definition of habitat preferences of the living foraminifera could not be investigated. Nevertheless, our study suggests that sedimentation processes also strongly impact the distribution of living foraminifera in the surface sediments in the area. The presence of stainable foraminiferal tests in the sediment was found to be restricted to the middle part of the transect (sample sites GH12-05 to GH12-12), where moderate current strength and wave action cause relatively stable sediment transport and deposition. In contrast, habitats with either a high- or a low-energy regime and thus with either sediment abrasion or strong accumulation were barren of living foraminifera. Examples are sites close to the Cut (sample sites GH12-13, GH12-14) and close to the Old Dock (i.e. sample sites GH12-01, GH12-02). This pattern suggests that a moderate energy regime is more hospitable for colonization by living foraminifera than higher-energy environments.

\subsection{The role of macroalgae Halimeda}

The relation between macrophyte biomass and foraminiferal assemblages is difficult to ascertain due to the carbonate encrustations of the algae, making estimations of biomass imprecise. However, our results indicate that when variation associated with grain size has been partialled out, the calcareous macroalgae Halimeda incrassata accounts for a significant fraction of the residual foraminiferal variation of the thanatocoenoses. In general, Halimeda is highly abundant in shallow bays in the northern Caribbean, especially on coarse or solid substrates (Brasier, 1975; Hillis-Colinvaux, 1980; Liddell et al., 1988; Davaud and Septfontaine, 1995). Halimeda is colonized by various epiphytic foraminifera (Wilson, 2007; Buchan and Lewis, 2009). Compared to seagrasses, e.g. Thalassia that forms up to $50 \mathrm{~cm}$ long leaves (Littler et al., 1989), the inhabitable surface area on $\mathrm{Hal}$ imeda thalli is small (thallus size of only $2-5 \mathrm{~cm}$; Littler et al., 1989; Multer and Clavijo, 2004), and Wilson (2008) reported a further areal limitation of those foraminiferal colonies that do not grow over the entire macrophyte leaf. In spite of its short life span of only a few weeks (Multer and Clavijo, 2004), Halimeda contributes between $15 \%$ and $50 \%$ of the total carbonate production in shallow, tropical marine realms (Scoffin and Tudhope, 1985; Liddell et al., 1988; Darroch, 2012, varying Multer and Clavijo, 2004). Due to thallus fragility, high-energy processes such as increased wave action during storms and strong currents may result in high spalling rates. Halimeda is reported as a primary producer of sea-floor sediments in nearshore environments and may also enhance the accumulation of particulate organic matter (Multer and Clavijo, 2004). Through its 
contribution to carbonate production it also influences habitat chemistry (Elliot et al., 1998), which can be expected to affect the local foraminiferal fauna and its preservation. The fact that Halimeda is primarily found in more open vegetation in our study area may also explain the link between $\mathrm{Hal}$ imeda and dead epiphytic foraminifera in the sediments: such areas are subject to sediment transport shown by the RDA to be the main controlling factor (Fig. 5). However, these areas also form the open vegetation still acting as a depositional area for the allochthonous foraminiferal specimens. If this hypothesis is correct, it would mean that Halimeda is not in itself the cause of the increased presence of dead epiphytic foraminifera in the sediment, but rather that the habitat dominated by Halimeda offers the best conditions for sediment deposition, including deposition of the empty foraminiferal tests transported form surrounding areas.

\subsection{Living and dead epiphytic foraminiferal assemblages}

As is quite common in tropical shallow marine habitats with sandy substrates, our sample sites showed distinctive variations in living epiphytic foraminiferal species distribution between sites with unvegetated, sparse colonization of calcareous macroalgae (mainly Halimeda and Penicillus) and those with dense seagrass meadows dominated by Thalassia and Syringodium (Table 2, Hillis-Colinvaux, 1980; Littler et al., 1989; Gerace et al., 1998; Buchan and Lewis, 2009; Farid et al., 2008). The number of living foraminifera on the macrophytes is overall low compared to some earlier studies (e.g. Wilson, 2008), but similar in magnitude to those found in other investigations (e.g. Wilson, 1989). The observed differences in species composition of the living foraminiferal assemblages between the various macrophytic habitats (Table 1) are likely controlled by habitat selection: macroalgal habitats are reported to be primarily colonized by pioneering foraminifera, while more diverse foraminiferal communities are found in seagrass meadows (Wilson and Ramsook, 2007). Furthermore, Morgan and Lewis (2010) observed substrate-dependent colonization in which calcareous algae were inhabited by the Rosalina-Discorbis group, whereas Planorbulina spp. dominated the Thalassia habitats. Walker et al. (2011) identified a foraminiferal community living attached to shells. However, our study shows some differences compared to these previous studies: in sparsely vegetated habitats at Grahams Harbour (typically M1 habitats) dominated by Halimeda, Udotea and Penicillus, specimens of Archaias angulatus, Sorites marginalis and Planorbulina sp. were found. Seagrass-covered habitats at Grahams Harbour (mainly M3 habitats) were primarily inhabited by the genera Cornuspira, Laevipeneroplis, Planorbulina and Sorites. A substrate-dependent foraminiferal assemblage of specific species could not be confirmed here and due to the limited macrophyte material in the present study it was not possible to statistically compare foraminiferal communities from algal and seagrass habitats. Morgan and Lewis (2010) suggest that current regimes may determine colonization by different epiphytic foraminiferal species. In our study the highest abundance of epiphytic foraminifera attached to macrophyte leaves was observed in the Thalassia habitat (M3) close to the Cut (GH12-12), where currents are strong. This supports the suggestion by Langer (1993) that vegetation density and diversity, including the relative algae-to-plant ratio, seems to control the distribution of epiphytic foraminifera that colonize shallow marine macrophyte habitats.

Due to a high calcification rate in the area (Mylroie and Carew, 2010), the surface sediments analysed here likely only contain biogenic material from the last few years, lessening the risk of mixing with older sediments of a potentially different palaeoenvironment, although some mixing due to hurricane activity cannot be ruled out. Moreover, macrophyte habitats, especially Thalassia meadows, have life spans lasting several years (Wilson, 2008) and they are relatively resistant to damage by storms and hurricanes (Thomas et al., 1961; Wilson and Ramsook, 2007). A stabilization of the sediment by rhizomes and a reduction of current energy due to leaves is especially supported in densely vegetated areas with Thalassia and Syringodium. Satellite images of our study site in fact suggest very little change in the marine vegetation cover in recent years (source: Google Earth, accessed to 20 February 2013, comparing satellite images within the previous 5 years). Thus, it is unlikely that any difference between epiphytic biocoenoses and thanatocoenoses at the same site is due to a change in macrophyte community over time. Hence, comparison of the living and dead epiphytic assemblages may be used to test the correlation between macrophytes and both living and dead epiphytic foraminiferal faunas.

Comparing the living epiphytic community from the macroalgae with the dead assemblages of epiphytic species in the sediment, both living and dead epiphytic-type I assemblages seem to follow a similar trend in abundance across habitats, with maximum densities in Thalassia-Syringodium (M3) beds (Figs. 3b, 4). However, a discrepancy is observed at sample station GH12-12, showing a high number of living specimens on the fibrous substrate, while the concentration of dead epiphytic (type I) foraminifera in the sediment is very low. The proximity of this site to the relatively highenergy regime near the current inflow suggests that the observed disproportion between the dead and living test density may be due to lateral sediment transport removing the dead epiphytic-type I foraminifera.

The comparison also illustrates some dissimilarity with respect to species dominance. Thalassia-Syringodiumvegetated habitats in strong current settings close to the Cut (Fig. 1b) are generally dominated by Archaias angulatus and Rosalina subaraucana in the dead epiphytic-type I assemblage, while Cornuspira sp. and the Rosalina-Discorbis group dominate the living community on the macrophyte leaves at the same sites. In the similar macrophyte community of the low-energy habitats proximal to the Old Dock 
(Fig. 1b) Sorites marginalis seems to dominate the living community, whereas the Rosalina-Discorbis group and Planorbulina $\mathrm{sp}$. characterize the dead epiphytic-type I assemblage. A similar scenario was noticed by Wilson (2008), who attributed this phenomenon to longshore transport of the macrophytes with their attached epiphytic biocoenosis through current activity or storms. Other possible explanations include differences in breakage, hydrodynamic properties, sedimentation rates or possibly even test production rates. Kloos (1980) suggested that the dominance of Sorites marginalis may be attributed to seasonal blooms, which highlights the possibility that the living foraminiferal assemblage is only a momentary snapshot of the environmental conditions in the habitat and does not represent the average living assemblage. Seasonal changes in epiphytic foraminiferal density on different macrophytes were in fact reported from shallow marine habitats on Nevis in the NE Caribbean by Wilson (2008).

\section{Conclusions}

Living and dead benthic foraminifera in surface sediments and from macroalgae were studied at 14 sample sites along a $500 \mathrm{~m}$ long nearshore transect at Grahams Harbour, San Salvador Island, Bahamas, to investigate the abundance and distribution of living vs. dead foraminifera in relation to habitat conditions. A main focus was on the comparison between epiphytic populations found living on the macroalgae and dead assemblages in the sediment, among others, to evaluate the reliability of epiphytic species in sediments as a proxy for past macroalgae and vegetation cover.

Foraminiferal tests of the thanatocoenosis were highly abundant and contributed to the grain matrix with up to 6200 tests per gram of surface sediment at Grahams Harbour. Habitats with the highest current and wave action regime contained less foraminifera per gram than areas with a more moderate energy environment, presumably due to abrasion and accumulation processes overprinting an autochthonous thanatocoenosis. Living (stained) foraminifera were much rarer with maximum abundances reaching 44 specimens per gram of surface sediment (1-3 living foraminifera per 100 dead foraminiferal tests). In addition to the oligotrophic conditions, the energy regimes at the sea floor seem to restrict the occurrence of living specimens as no living foraminifera were found in areas with either a very high (inducing grain abrasion) or a low current strength (resulting in grain accumulation), i.e. close to the tidal inflow and distal of the tidal inflow, respectively.

Our study showed that despite the fact that the foraminiferal assemblage living on the macrophytes was dominated by Sorites marginalis, none were found in the dead assemblages in the sediments; the same was the case for Peneropolis sp. Thus, there was a significant difference in the living epiphytic assemblage and the dead as- semblage. Multivariate analyses suggest that the thanatocoenoses of epiphytic-type I (permanently to temporary attached) foraminifera in the shallow-water sediments of this tropical island are mainly determined by sediment transport, i.e. sorting by grain size through sediment transport. Specimens were overall well preserved and we also find smaller, more fragile taxa such as Spirillina sp. and Elphidium sp. in the thanatocoenosis. We could therefore not confirm postmortem test preservation as a main cause for the differences between biocoenosis and thanatocoenosis as previously reported from other areas (e.g. Martin and Wright, 1988).

The area of macrophyte cover and diversity also seems to affect the foraminiferal abundance to some extent. There was no discernible significant link between habitat type (density of vegetation) and the frequency or concentration of epiphytic foraminifera in the sediment. However, our statistical analyses found the macrophyte Halimeda incrassata to have a significant correlation with the foraminiferal assemblage composition, indicating that this macrophyte may act as a sediment trap.

Consequently, our study suggests that in shallow-water tropical areas the epiphytic (type I) component of a dead foraminiferal assemblage may not always give a reliable indication of the past macrophyte cover in the region. It furthermore indicates that in carbonate platform regions, epiphytic species should only be used cautiously as direct indicators of past in situ macroalgae growth, as previously suggested by Reich et al. (2015) and references herein.

Data availability. All main data are already included in the paper. Further information and raw data can be requested from the authors.

Author contributions. AF and MSS designed the study, and AF carried out the fieldwork and foraminiferal analyses. BVO and AF carried out the statistical treatments. AF wrote the first draft of paper, and all authors provided comments and corrections.

Competing interests. The authors declare that they have no conflict of interest.

Acknowledgements. We gratefully thank Dena Smith, Michal Kowalewski and Thomas Rothfuss as well as the staff of the Gerace Research Centre, San Salvador, for their assistance during the field work on San Salvador. We thank Simon Darroch for his help and suggestions during the early stage of this study. The Paleontological Society, Graduate School of Science and Technology (GSST) at Aarhus University, Denmark, as well as the Independent Research Fund Denmark projects TROPOLINK, OCEANHEAT and G-ICE (project nos. 09-069833/FNU, 12$126709 / \mathrm{FNU}$ and 7014-00113B/FNU), and the Knud-Højgaard Fond in Denmark are gratefully thanked for their financial support. The two reviewers, Simon Darroch and Ronald Lewis, as well 
as the journal editor Laia Alegret are thanked for their thorough comments and constructive suggestions for improving the paper.

Edited by: Laia Alegret

Reviewed by: Simon Darroch and Ronald Lewis

\section{References}

Adams, R. W.: General guide to the geological features of San Salvador, in: Field Guide to the Geology of San Salvador, edited by: Gerace, D. T., Bahamian Field Station, San Salvador, 66, 1980.

Alve, E.: Colonization of new habitats by benthic foraminifera: a review, Earth-Sci. Rev., 46, 167-185, https://doi.org/10.1016/S0012-8252(99)00016-1, 1999.

Armstrong, M. E. and Miller, A. I.: Modern carbonate sediment production and its relation to bottom variability, Grahams Harbor, San Salvador, Bahamas, in: Proceedings of the Fourth Symposium on the Geology of The Bahamas, edited by: J. Mylroie, J., Bahamian Field Station, San Salvador, 23-32, 1988.

Beck, S.: Distribution of benthic foraminifera at North Point, Graham's Harbour, San Salvador Island, Bahamas, in: Fourth Keck Research Symposium in Geology, edited by: Fox, W. T., Mertzman, S. A., and Woodard, H. H., Beloit College, Beloit, Wisconsin, 47-51, 1991.

Berkeley, A., Perry, C. T., Smithers, S. G., and Horton, B. P.: The spatial and vertical distribution of living (stained) benthic foraminifera from a tropical, intertidal environment, north Queensland, Australia, Mar. Micropaleontol., 69, 240-261, https://doi.org/10.1016/j.marmicro.2008.08.002, 2008.

Bock, W. D., Lynts, G. W., Smith, S., Wright, R., Hay, W. W., and Jones, J. I.: A symposium of recent south Florida foraminifera, Memoir 1, Miami Geological Society, Miami, 245, 1971.

Boltovskoy, E. and Wright, R.: Recent foraminifera, Dr. W. Junk b.v., The Hague, 515, 1976.

Brasier, M. D.: An outline history of seagrass communities, Paleontology, 18, 681-702, 1975.

Buchan, O. L.: Relationships between large benthic foraminifera and their seagrass habitats, San Salvador, Bahamas, Auburn University, Alabama, 100, 2006.

Buchan, O. L. and Lewis, D. L.: Recent benthic foraminifera as indicators of seagrass-bed characteristics, San Salvador, Bahamas: The addition of taphonomy, Geologic Problem Solving with microfossils: A volume in honor of Garry D. Jones, SEPM Special Publication, 93, 83-92, 2009.

Caribbean Hurricane Network: Climatology of Caribbean Hurricanes; http://stormcarib.com/climatology/MYSM_all_isl.htm (last access: 12 June 2012), 2011.

Colby, N. D. and Boardman, M. R.: Depositional evolution of windward, high-energy lagoon, Graham's Harbor, San Salvador, Bahamas, J. Sediment. Petrol., 59, 819-834, 1989.

Culver, S. J. and Buzas, M. A.: Distribution of recent benthic foraminifera off the Pacific Coast of Mexico and Central America, Smithsonian Contributions to Marine Sciences, 30, 1-184, https://doi.org/10.5479/si.01960768.30.1, 1982.

Curran, H. A., Delano, P., White, B., and Barrett, M.: Coastal Effects of Hurricane Floyd on San Salvador Island, Bahamas, in: Proceedings of the 10th Symposium on the Geology of The Bahamas, edited by: Greenstein, B. J. and Carney, C. K., Bahamian
Field Station, San Salvador Island, Bahamas, Ft. Lauderdale, Florida, 1-12, 2001.

Cushman, J. A.: Shallow-water foraminifera of the Tortugas region, Carnegie Institution of Washington, Washington, 17, 3-85, 1922.

Cushman, J. A.: The foraminifera of the Atlantic Ocean, Part 8: Rotaliidae, Amphisteginidae, Calcarinidae, Cymbalopoerttidae, Globorotaliidae, Anomalinidae, Planorbulinidae, Rupertiidae, and Homotremidae, Bulletin of the US National Museum, 104, 1-179, 1931.

Darroch, S. A. F.: Carbonate facies control on the fidelity of surfacesubsurface agreement in benthic foraminiferal assemblages: implications for index-based palaeoecology, Palaios, 27, 137-150, https://doi.org/10.2110/palo.2011.p11-027r, 2012.

Darroch, S. A. F., Locatelli, E. R., McCoy, V. E., Clark, E. G., Anderson, R. P., Targan, L. G., and Hull, P. M.: Taphonomic disparity in foraminifera as a paleo-indicator for seagrass, Palaios, 31, 242-258, 2016.

Davaud, E. and Septfontaine, M.: Post-mortem onshore transportation of epiphytic foraminifera: recent examples from the Tunesian coastline, J. Sediment. Res., 65, 136-142, https://doi.org/10.1306/D426804F-2B26-11D78648000102C1865D, 1995.

Debenay, J.-P. and Payri, C. E.: Epiphytic foraminiferal assemblages on macroalgae in reefal environments of New Caledonia, J. Foramin. Res., 40, 36-60, 2010.

Elliot, M., Nedwell, S., Jones, N. V., Read, S., Cutts, N. D., and Hemingway, K. L.: Intertidal sand and mudflats and subtidal mobile sandbanks (Volume II): An overview of dynamic and sensitivity characteristics for conservation management of marine SACs, Scottish Association for Marine Science, Oban, for the UK Marine SAC project, available at: http://www.ukmarinesac. org.uk/pdfs/sandmud.pdf (last access: 18 October 2018), 1998.

Farid, M. A., Rasidi, S., and Patria, M. P.: The community structure of seagrass in Enggano Islands, Bengkulu, Marine Research Indonesia, 33, 7-10, https://doi.org/10.14203/mri.v33i1.501, 2008.

Fujita, K.: A field colonization experiment on smallscale distributions of algal symbiont-bearing larger foraminifera on reef rubble, J. Foramin. Res., 34, 168-179, https://doi.org/10.2113/34.3.169, 2004.

Fujita, K. and Hallock, P.: A comparison of phytal substrate preferences of Archaias angulatus and Sorites orbiculus in mixed macroalgal-seagrass beds in Florida Bay, J. Foramin. Res., 29, 143-151, https://doi.org/10.2113/gsjfr.29.2.143, 1999.

Gerace, D. T., Ostrander, G. K., and Smith, G. W.: Environment and development in coastal regions and in small islands, in: CARICOMP - Caribbean Coral Reef, Seagrass and Mangrove Sites, Coastal Region and Small Island Papers, 3, UNESCO, Paris, 347, 1998.

Ginsburg, R. N. and Lowenstam, H. A.: The influence of marine bottom communities on the depositional environment of sediments, J. Geol., 66, 310-318, https://doi.org/10.1086/626507, 1958.

Gould, J. and Vermette, S.: Characterizing the beach morphology of San Salvador, Middle States Geographer, 38, 61-68, 2005.

Hearty, P. J. and Kindler, P.: New perspectives on Bahamian Geology: San Salvador Islands, J. Coastal Res., 9, 577-594, 1993.

Hickmann, C. S.: Evolution on flexible hard substrates: Metazoan adaptations for life on seagrasses (abstract), Geological Society of America, 37, 405, 2005. 
Hillis-Colinvaux, L.: Ecology and taxonomy of Halimeda: Primary producers of coral reefs, Adv. Mar. Biol., 17, 1-327, https://doi.org/10.1016/S0065-2881(08)60303-X, 1980.

Hine, A. C., Wilbur, R. J., and Neumann, A. C.: Carbonate sand bodies along contrasting shallow bank margins facing open seaways in northern Bahamas, Am. Assoc. Petr. Geol. B., 65, 262290, 1981.

Hofker, J.: Foraminifera dentate. Foraminifera of Santa Cruz and Thatch-Island Virginia-Archipelago West Indies, E. Munksgaard, Copenhagen, 237, 1956.

Jackson, J. B. C., Kirby, M. X., Berger, W. H., Bjorndal, K. A., Botsford, L. W., Bourque, B. J., Bradbury, R. H., Cooke, R., Erlandson, J., Estes, J. A., Hughes, T. P., Kidwell, S., Lange, C. B., Lenihan, H. S., Pandolfi, J. M., Peterson, C. H., Steneck, R. S., Tegner, M. J., and Warner, R. R.: Historical overfishing and the recent collapse of the coastal ecosystems, Science, 293, 629-638, https://doi.org/10.1126/science.1059199, 2001.

Kloos, D. P.: Studies on the foraminifer Sorites orbiculus, Geologie en Mijnbouw, 59, 375-383, 1980.

Kotler, E., Martin, R. E., and Liddell, W. D.: Experimental analysis of abrasion and dissolution resistance of modern reef-dwelling foraminifera: implications for the preservation of biogenic carbonate, Palaios, 7, 244-276, https://doi.org/10.2307/3514972, 1992.

Langer, M. R.: Epiphytic foraminifera, Mar. Micropaleontol., 20, 235-265, https://doi.org/10.1016/0377-8398(93)90035-V, 1993.

Liddell, W. D., Ohlhorst, S. L., and Boss, S. K.: The significance of Halimeda as a space-occupier and sediment-producer, 1-750 m, North Jamaica, Proceedings of the 6th International Coral Reef Symposium, Australia, 3, 127-132, 1988.

Lipps, J. H.: Biotic interactions in benthic foraminifera, in: Biotic interactions in recent and fossil benthic communities, edited by: Tevesz, M. J. S. and McCall, P. C., Plenum Publishing Company, New York, USA, 331-376, 1983.

Lipps, J. H.: Predation on foraminifera by coral reef fish; taphonomy and evolutionary implications, Palaios, 3, 315-326, https://doi.org/10.2307/3514660, 1988.

Lipschultz, F., Bates, N. R., Carlson, C. A., and Hansell, D. A.: New production in the Sargasso Sea: History and current status, Global Biogeochem. Cy., 16, 1-17, https://doi.org/10.1029/2000GB001319, 2002.

Littler, D. S. and Littler, M. M.: Caribbean reef plants. An identification Guide to the Reef Plants of the Caribbean, Bahamas, Florida and Gulf of Mexico, Off shore Graphics, Washington, $542,2000$.

Littler, D. S., Littler, M. M., Bucher, K. E., and Norris, J. N.: Marine plants of the Caribbean. A field guide from Florida to Brazil, Smithsonian Institution Press, Washington, 272, 1989.

Loeblich, A. R. and Tappan, H.: Foraminiferal genera and their classification, Van Nostrand Reinhold Co., New York, 868, 1988.

Martin, R. E.: Habitat and distribution of the foraminifer Archais angulatus (Fichtel and Moll) (Miliolina, Soritidae), northern Florida Keys, J. Foramin. Res., 16, 201-206, https://doi.org/10.2113/gsjfr.16.3.201, 1986.

Martin, R. E. and Wright, R. C.: Information loss in the transition from life to death assemblages of foraminifera in back reef environments, Key Largo, Florida, J. Paleontol., 62, 399-410, https://doi.org/10.1017/S0022336000059163, 1988.
Miller, A. I.: Spatial resolution in subfossil molluscan remains: implications for paleobiological analyses, Paleobiology, 14, 91103, 1988.

Morgan, J. L. and Lewis, R. D.: Benthic foraminiferal assemblages at Cut Cay: A microcosm study of the effect of water energy and substrate preference, San Salvador, Bahamas, in:Proceedings of the 14th Symposium on the Geology of the Bahamas and other Carbonate Regions, edited by: Siewers, F. and Martin, J., Gerace Research Centre, San Salvador, Bahamas, 150-162, 2010.

Multer, G. H. and Clavijo, I.: Halimeda investigations: Progress and Problems, NOAA Miami Regional Library, Miami, 117127, 2004.

Murray, J. W.: The foraminifera of the Persian Gulf 6. Living forms in the Abu Dhabi region, J. Nat. Hist., 4, 55-67, 1970.

Murray, J. W.: Ecology and palaeoecology of benthic foraminifera, Longman Scientific \& Technical, Essex, 397, 1991.

Mylroie, J. E. and Carew, J. L.: Field guide to the geology and karst geomorphology of San Salvador Island, Gerace Research Centre, San Salvador, Bahamas, 89, 2010.

Park, L. E.: Comparing two long-term hurricane frequency and intensity records from San Salvador Island, Bahamas, J. Coastal Res., 28, 891-902, https://doi.org/10.2112/JCOASTRES-D-11$00065.1,2012$.

Reich, S., Di Martino, E., Todd, J. A., Wesselingh, F. P., and Renema, W.: Indirect paleo-seagrass indicators (IPSIs): a review, Earth-Sci. Rev., 143, 161-186, https://doi.org/10.1016/j.earscirev.2015.01.009, 2015.

Renema, W.: Habitat variables determining the occurrence of large benthic foraminifera in the Berau area (East Kalimantan, Indonesia), Coral Reefs, 25, 351-359, 2006.

Renema, W. and Troelstra, S. R.: Larger foraminifera distribution on a mesotrophic carbonate shelf in SW Sulawesi (Indonesia), Palaeogeogr. Palaeocl., 175, 125-146, https://doi.org/10.1016/S0031-0182(01)00389-3, 2001.

Ribes, T., Salvador, H. J. R., and Gracia, M. P.: Foraminiferal colonization on artificial seagrass leaves, J. Foramin. Res., 30, 192201, https://doi.org/10.2113/0300192, 2000.

Robinson, M. C. and Davis, R. L.: San Salvador Island GIS Database, The University of New Haven and Bahamian Fieldstation, San Salvador Island, Bahamas, 1999.

Scoffin, T. P.: The trapping and binding of subtidal carbonate sediments by marine vegetation in Bimini Lagoon, Bahamas, J. Sediment. Petrol., 4, 81-93, 1970.

Scoffin, T. P. and Tudhope, A. W.: Sedimentary environments of the central region of the Great Barrier Reef of Autsralia, Coral Reefs, 4, 81-93, 1985.

Shaklee, R. V.: In Columbus foodsteps: Geography of San Salvador Island, The Bahamas, Bahamas Field Station, San Salvador, 65, 1994.

Steinker, D. C. and Clem, K. V.: Some near-shore foraminiferal assemblages from phytal and bottom sediments, Bermuda, The Compass, 61, 98-115, 1984.

Swinchatt, J. P.: Significance of constituent composition, texture, and skeletal breakdown in some recent carbonate marine sediments, J. Sediment. Petrol., 35, 71-90, 1965.

Taylor, J. D. and Lewis, M. S.: The flora, fauna and sediments of the marine grass beds of Mahe Seychelles, J. Nat. Hist., 4, 199-220, https://doi.org/10.1080/00222937000770201, 1970. 
ter Braak, C. J. F. and Šmilauer, P.: CANOCO version 4.5, Biometrics-Plant Research International, Wageningen, 2002.

Thomas, F. C. and Schafer, C. T.: Distribution and transport of some common foraminiferal species in the Minas Basin, Eastern Canada, J. Foramin. Res., 12, 24-38, https://doi.org/10.2113/gsjfr.12.1.24, 1982.

Thomas, L. P., Moore, D. R., and Work, R. C.: Effects of hurricane Donna on turtle grass beds of Biscayne Bay, Florida, Bulletin Marine Science Gulf Caribbean, 11, 191-197, 1961.

Walker, S. E., Parsons-Hubbard, K., Richardson-White, S., Brett, C., and Powell, E.: Alpha and beta diversity of encrusting foraminifera that recruit to long-term experiments along a carbonate platform-to-slope gradient: Paleoecological and paleoenvironmental implications, Palaeogeogr. Palaeocl., 312, 325-349, https://doi.org/10.1016/j.palaeo.2011.04.028, 2011.

Walton, W. R.: Techniques for recognition of living foraminifera, Contribution from the Cushman Foundation for Foraminiferal Research, 3, 56-60, 1952.

Waszczak, R. F. and Steinker, D. C.: Paleoenvironmental and paleoecological implications of recent foraminiferan distributional patterns in the lower Florida Keys, in: Symposium on South Florida Geology, edited by: Maurrasse, F., Miami Geological Society, Memoirs, 3, 203-225, 1978.

Wilson, B.: Epiphytal foraminiferal assemblages on the leaves of the seagrasses Thalassia testudinum and Syringodium filiforme, Caribb. J. Sci., 34, 131-132, 1998.
Wilson, B.: Benthonic foraminifera as a tool in environmental quality control: Two Caribbean examples, Geological Society of Trinidad and Tobago Conference and Exhibition, 10-13 July, Port-of-Spain, Trinidad, Geological Society of Trinidad and Tobago, Port of Spain, Trinidad, 2000.

Wilson, B.: The environmental significance of Archaias angulatus (Miliolida, foraminifera) in sediments around Nevis, West Indies, Caribb. J. Sci., 39, 209-214, 2006.

Wilson, B.: Guilds among epiphytal foraminifera on fibrous substrates, Nevis, West Indies, Mar. Micropaleontol., 63, 1-18, https://doi.org/10.1016/j.marmicro.2006.10.001, 2007.

Wilson, B.: Population structures among epiphytal foraminiferal communities, Nevis, West Indies, J. Micropaleontol., 27, 63-73, https://doi.org/10.1144/jm.27.1.63, 2008.

Wilson, B.: Effect of Hurricanes on guilds of nearshore epiphytal foraminifera, Nevis, West Indies, J. Foramn. Res., 40, 327-343, https://doi.org/10.2113/gsjfr.40.4.327, 2010.

Wilson, B. and Ramsook, A.: Population densities and diversities of epiphytal foraminifera on nearshore substrates, Nevis, West Indies, J. Foramin. Res., 37, 213-222, 2007.

Winland, H. D. and Matthews, R. K.: Origin and significance of grapestone, Bahamas Islands, J. Sediment. Petrol., 44, 921-927, https://doi.org/10.2113/gsjfr.37.3.213, 1974.

Wright, R. C.: Foraminiferal Ecology in the Black Reef Environment, Molasse Reef, Florida, PhD Dissertation, University of Illinois, 124 p., 1964.

Wright, R. C. and Hay, W. W.: The abundance and distribution of foraminifers in a back-reef environment, Molasses Reef, Florida, Miami Geological Society Memoir, 1, 121-174, 1971. 